\title{
Cobalt-Doping Enhancing Electrochemical Performance of Silicon/Carbon Nanocomposite as Highly Efficient Anode Materials in Lithium-Ion Batteries
}

\author{
Muhammad Idrees, ${ }^{1 \dagger}$ Liqiang Liu, ${ }^{1 \dagger}$ Saima Batool, ${ }^{1}$ Hebin Luo, ${ }^{2}$ Jin Liang, ${ }^{1}$ Benbin Xu, ${ }^{3}$ Steven Wang $^{4}$ and Jie Kong ${ }^{1 *}$
}

Sustainable, renewable and environmental friendly anode materials are key factors to energy storage devices. We report a novel metal-doping strategy to enhance electrochemical performance of silicon/carbon nanocomposite $(\mathrm{Co}-\mathrm{Si} / \mathrm{C})$ anode via pyrolysis of cobalt-coordinated poly(dimethylsilyene)diacetylenes. The Co-Si/C nanocomposite anodes exhibited promising superior cyclic properties and kept a high discharge capacity of about $1105 \mathrm{mAh} \mathrm{g}^{-1}$. They maintained a specific capacity of $905 \mathrm{mAh} \mathrm{g}^{-1}$ after 100 cycles at $100 \mathrm{~mA} \mathrm{~g}^{-1}$ with an average coulombic efficiency of $81.9 \%$ and a high specific capacity of $540 \mathrm{mAh} \mathrm{g}^{-1}$ after 1000 cycles at $500 \mathrm{~mA} \mathrm{~g}^{-1}$ with an average coulombic efficiency of $99 \%$. The Co-Si/C anode composite preserved the structural integrity after the electrochemical tests, demonstrating the potential of efficient and stable electrochemical performance.

Keywords: Lithium ion batteries; Anode materials; Silicon/carbon nanocomposite; Metal-doping

Received 22 January 2019, Accepted 1 February 2019

DOI: $10.30919 / \mathrm{es} 8 \mathrm{~d} 798$

\section{Introduction}

To meet the increasing demand of portable storage devices for daily life, tremendous efforts have been made to improve sustainable storage systems. ${ }^{1,2}$ Lithium ion batteries (LIBs) are an ideal ubiquitous power source for portable an electronic device as high efficiency, attractive life span and environment friendly. ${ }^{3}$ For the commercial point of view, LIBs have been used in electric vehicles and mobile electronics. Many efforts have been triggered to construct the anode material with superior performance for LIBs. ${ }^{47}$ For example, transition metal oxides (TMOs) have been attracted as potential host structures material due to their lithium storage capacity and electrochemically inactive nature. ${ }^{8-13}$ However, it is observed thatthe fabrication of their insulating layers and structure delithiation has led to the batteries with lower specific capacities than theoretical values.

In this regard, various coordination polymers (CPs) having a selfassembled dimensional network of metal clusters are subsequently utilized as active anode material. ${ }^{14}$ Tarascon's group reported that a series of $\mathrm{CP}$ based on conjugated dicarboxylates lithium $\mathrm{Li}_{2} \mathrm{C}_{8} \mathrm{H}_{4} \mathrm{O}_{4}$ and

${ }^{1}$ MOE Key Laboratory of Materials Physics and Chemistry in Extraordinary Conditions, Shaanxi Key Laboratory of Macromolecular Science and Technology, School of Natural \& Applied Sciences, Northwestern Polytechnical University, Xi'an, 710072, China

${ }^{2}$ Fujian Blue Ocean \& Black Stone Technology Co., Ltd., Changtai, Fujian Province, 363900, China

${ }^{3}$ Mechanical and Construction Engineering, Faculty of Engineering and Environment, Northumbria University, Newcastle upon Tyne, NE1 8ST, $U K$

${ }^{4}$ School of Chemical Engineering and Advanced Materials, Newcastle University, Newcastle Upon Tyne, NE1 7RU, UK

Those authors contribute equally

*E-mail: kongjie@nwpu.edu.cn
$\mathrm{Li}_{2} \mathrm{C}_{6} \mathrm{H}_{4} \mathrm{O}_{4}$ have an average capacity of $\sim 300$ and $\sim 500 \mathrm{mAh} \mathrm{g} \mathrm{g}^{-15}$ These anodes have only the ability of reacting two lithium ions per formula unit at potential of $0.8 \mathrm{~V}^{16}$ Fei et al. also observed that the reversible capacity of the manganese dicarboxylates remained $\sim 457.2 \mathrm{mAh} \mathrm{g}^{-1}$ at $500 \mathrm{~mA} \mathrm{~g}{ }^{-1}$ for next 100 cycles. $^{17}$ Asakura et al. ${ }^{18}$ reported that the cyanide-bridged CPs enhance the cycle ability of the electrode. The phenomenon is ascribed to the core@shell heterostructure that increases the lithium ion mobility.

To achieve high performance electrochemical performance of the CPs, many researchers focussed on designing a special coordinated structure, which aims to reduce the diffusion path and increases the surface area for lithium ions. It has a notable effect on restraining the volume expansion and increasing electron conductivity when metal oxides combined with carbon materials. ${ }^{19,20} \mathrm{Up}$ to now, many considerable references described Li-CPs based materials such as carboxylates, cobalt and manganese, which possessed the capacity of $100 \mathrm{mAhg}^{-1}, 545 \mathrm{mAhg}^{-1}$, and $390 \mathrm{mAh} \mathrm{g}^{-1}$, respectively. ${ }^{21-23}$ Recently, Guo et al. $^{24}$ and Zeng et al. ${ }^{25}$ reported $\left[\mathrm{Li}_{6}(\mathrm{pda})_{3}\right] \cdot 2 \mathrm{EtOH}$ based pyridienedicarboxylate ligand and $\left[\mathrm{Li}_{2}\left(\mathrm{C}_{14} \mathrm{H}_{6} \mathrm{O}_{4}\right)\right]$, which exhibited the discharge capacity of $\sim 164 \mathrm{mAhg}^{-1}$ and $126 \mathrm{mAhg}^{-1}$, respectively.

The nano-structured metal oxides CPs mentioned above can be applied as potential anode to improve the electrochemical performance of LIBs. ${ }^{26,27}$ Yet, appropriate preparation procedure, suitable precursor and high performance are still limited. Herein, we report a novel metaldoping strategy to enhance electrochemical performance of silicon/carbon nanocomposite $(\mathrm{Co}-\mathrm{Si} / \mathrm{C})$ anode via pyrolysis of cobaltcoordinated poly(dimethylsilyene)diacetylenes. Cobalt-containing silicon/carbon nanocomposite $(\mathrm{Co}-\mathrm{Si} / \mathrm{C})$ anode materials were designedvia pyrolysis of the as-synthesized cobalt-coordinated poly(dimethylsilyene)diacetylenes (Co-PDSDA). Benefiting from the amorphous $\mathrm{Si} / \mathrm{C}$ structure and cobalt nanocrystals, the $\mathrm{Co}-\mathrm{Si} / \mathrm{C}$ nanocomposite exhibits a high specific capacity of $905 \mathrm{mAh} \mathrm{g}^{-1}$ after 100 cycles at $100 \mathrm{~mA} \mathrm{~g}^{-1}$ with an average coulombic efficiency of $81.9 \%$ 
and a specific capacity of $540 \mathrm{mAh} \mathrm{g}^{-1}$ after 1000 cycles at $500 \mathrm{~mA} \mathrm{~g}^{-1}$ with an average coulombic efficiency of $99 \%$.

\section{Experimental}

\section{Materials}

The chemicals and reagents were used as received without any further purification. n-Butyl lithium (n-BuLi) (2.5 M), dimethyldichlorosilane (MSDS) $\left(\mathrm{Si}\left(\mathrm{CH}_{3}\right) \mathrm{Cl}_{2}>99.5 \%\right)$, (hexachloro-1, 3-butadiene $>96 \%$ ) and chlorotrimethylsilane (TCE) $\left.\left(\mathrm{CH}_{3}\right)_{3} \mathrm{SiCl}>98 \%\right)$ were obtained from Alfa Aesar, Tianjin, China. Dicobalt Octacarbonyl $\left(\mathrm{Co}_{2}(\mathrm{CO})_{8}\right)$ stabilized through $1-5 \%$ hexane was received from Tokyo Chem. Industry Co., Ltd.Acetonitrile $\left(\mathrm{C}_{2} \mathrm{H}_{3} \mathrm{~N}\right)$ was purchased from Guangdong Guanghua Sci-Tech Co., Ltd. China. The tetrahydrofuran (THF) was purified with $\mathrm{Na}$ /benzophenone under $\mathrm{Ar}$.

\section{Synthesis of $\left[\mathrm{SiCo}_{2}(\mathrm{CO})_{6} \mathrm{C}_{5} \mathrm{H}_{6}\right]_{\mathrm{n}}(\mathrm{Co}-\mathrm{PDSDA})$}

The PDSDA and Co-PDSDA were synthesized according to the reported procedure of our group. ${ }^{28,29}$ The standard Schlenk method was applied for the synthesis of the material. A pre-dried $250 \mathrm{~mL}$ flask was filled with THF $(60 \mathrm{~mL}), \mathrm{n}-\mathrm{BuLi}(42.51 \mathrm{~g}, 0.14 \mathrm{~mol})$ and temperature was maintained at $-78^{\circ} \mathrm{C}$ (in an acetone/ice bath). The hexachloro-1, 3butadiene $(9.456 \mathrm{~g}, 0.035 \mathrm{~mol})$ was further added. After the continuous stirring for $12 \mathrm{~h}$ at $25{ }^{\circ} \mathrm{C}$, dichlorodimethylsilane (4.578 g, $0.035 \mathrm{~mol}$ ) was added into the flask to initiate the formation of PDSDA. Furthermore, the PDSDA was mixed in a desired quantity of toluene and the lithium chloride was extracted out. After solvent evaporation, the precursor was precipitated in methanol, filtered out and dried with $47 \%$ yield. The $\mathrm{Co}_{2}(\mathrm{CO})_{8}$ was added together with $5.0 \mathrm{~g}$ of PDSDA according to the 5.5, 7.5 and $9.5 \mathrm{~mol} \%$ of the quantity of alkynyl groups under an argon atmosphere. After reaction, the mixture was sat overnight and the solvent was vanished at room temperature. The concentrated solution was mixed with acetonitrile under constant stirring. The precipitate of Co-PDSDA was obtained and washed three times before drying at $30^{\circ} \mathrm{C}$ for $24 \mathrm{~h}$.

\section{Preparation of $\mathrm{Co}-\mathrm{Si} / \mathrm{C}$ nanocomposites}

The vacuum evacuated $2.5 \mathrm{~g}$ of each Co-PDSDA of various cobalt content ratios were covered with graphite sheet to prevent out and then shifted into a furnace (GSL-1100X, Kejing New Mater, Ltd., Hefei, China). Primarily, the cross-linking started at $25^{\circ} \mathrm{C}$ to $300{ }^{\circ} \mathrm{C}$ a heating rate of $2 \mathrm{~K} \mathrm{~min}^{-1}$ for $2 \mathrm{~h}$ holding time, subsequently pyrolysis at $800{ }^{\circ} \mathrm{C}$ at $5{ }^{\circ} \mathrm{C} \min ^{-1}$ for $3 \mathrm{~h}$. Finally, the temperature was decreased with a heating rate of $5 \mathrm{~K} \mathrm{~min}^{-1}$. After pyrolysis of Co-PDSDA, the obtained $\mathrm{Co}-\mathrm{Si} / \mathrm{C}$ nanocomposites were ball-milled, sieved down to $20-25 \mu \mathrm{m}$ and labelled as $\mathrm{Co}-\mathrm{Si} / \mathrm{C} 5.5 \%, \mathrm{Co}-\mathrm{Si} / \mathrm{C} \quad 7.5 \%$ and $\mathrm{Co}-\mathrm{Si} / \mathrm{C} \quad 5.5 \%$, respectively, as shown in the Table 1 .

\section{Structure characterization}

The thermogravimetric analysis (TGA) of Co-PDSDA was obtained on a (METTLER TGA/DSC $1 \mathrm{SF} / 1382$, USA) thermal analyser at $10{ }^{\circ} \mathrm{C}$ $\mathrm{min}^{-1}$ heating rate in an argon atmosphere. The $\mathrm{Co}-\mathrm{Si} / \mathrm{C}$ nanocomposites were carried out on a Powder X-ray diffraction (PXRD, Bruker D8 ADVANCED, $\mathrm{Cu} \mathrm{K} \alpha(\lambda=0.154056 \mathrm{~nm})$ radiation at a scanning speed of $0.015^{\circ} \mathrm{s}^{-1}$ between $10^{\circ}$ to $80^{\circ}$ radiation. A $40 \mathrm{kV}$ and $100 \mathrm{~mA}$ were selected as an operating voltage and the current rate, respectively. The $\mathrm{Co}-\mathrm{Si} / \mathrm{C}$ nanocomposite microstructure, shape and size were determined by transmission electron microscope (TEM, Tecnai G2 F20 S-TWIN, USA), using an accelerating voltage of $200 \mathrm{kV}$. A Fourier transform infrared (FT-IR) spectrum was recorded on a Thermo Fisher spectrophotometer using the $\mathrm{KBr}$ pellets. Raman microscopy was conducted on a Jobin-Yvon Lab or Raman HR-800 spectrometer with argon ion laser $(\lambda=514 \mathrm{~nm})$ in ambient oxygen. To investigate the size and surface morphology, scanning electron microscopy (SEM, HITACHI S-4800, Japan) was employed as a tool for the as-prepared nanocomposites. The elemental content was observed by GENENIS4000 energy dispersive X-ray spectroscopy (EDS). The cells were disassembled at the delithiation phase and specimens were scraped from the working electrodes and washed with an ethanol solution for post characterization. The X-ray photoelectron spectrum (XPS) was recorded on an ESCALAB 250XI (Thermo Scientific, UK) instrument with a background vacuum better than $2 \times 10^{-9}$ mbar. Monochromatic $\mathrm{Al} \mathrm{K}_{\alpha}$ (energy $h v=1486.68 \mathrm{eV}$ ) radiation at a power of $164 \mathrm{~W}(10.8$ $\mathrm{mA}$ and $15.2 \mathrm{kV}$ ) with a spot size of $500 \mu \mathrm{m}$ was used for analysis.

\section{Electrochemical measurements}

The electrochemical characterization of as-obtained $\mathrm{Co}-\mathrm{Si} / \mathrm{C}$ nanocomposite powders (20-25 $\mu \mathrm{m}$ meshes) was examined using a CR2025 type cells. The working electrodes were prepared by compressing a mixture of $80 \mathrm{wt} \% \mathrm{Co}-\mathrm{Si} / \mathrm{C}$ composite, $10 \mathrm{wt} \%$ acetylene black Super $P \circledR \quad$ (Timcal Ltd., Switzerland) and $10 \mathrm{wt} \%$ poly(vinylidene fluoride) (PVDF, Taiyuan, China) binder. The mixture was sonicated in N-methyl pyrrolidinone (NMP) solvent to make homogenous slurry,andthen it was coated onto a $15 \mu \mathrm{m}$ of rough side copper foil current collector, dried under the vacuum at $80{ }^{\circ} \mathrm{C}$ for and pressed at $20 \mathrm{MPa}$. The coin-cells were manufactured in high pure argon filled glove box (Super (1220/750/900 Mikrouna, China) by stacking a polypropylene separator (Celgard 2400 porous, $25 \mu \mathrm{m}$ ), metallic lithium (referenced electrode) and $1 \mathrm{~mol} \mathrm{~L}^{-1} \mathrm{LiPF}_{6}$ ethylene carbonate (EC)/dimethylcarbonate (DMC) (VEC: VDMC $=1: 1)$ (Zhangjiagang, China). The electrochemical charge/discharge experiments were measured using a LANHE CT2001A Multi-channel Battery Tester (Wuhan, China) in the voltage limits of 0.01 to $3.0 \mathrm{~V}$ vs $\mathrm{Li} / \mathrm{Li}^{+}$. Cycler voltammograms $(\mathrm{CVs})$ were tested on a $\mathrm{CHI} 600 \mathrm{E}(\mathrm{CH}$ Instruments, Shanghai, China) electrochemical workstation in the range between 0.01 to $3.0 \mathrm{~V}$ vs $\mathrm{Li}^{2} / \mathrm{Li}^{+}$with a sweep speed of $0.04 \mathrm{mV} \mathrm{s}$. Electrochemical impedance spectra (EIS) were measured on a CHI600E (CHI Instruments, Shanghai, China) in the range between $10^{5}-0.01 \mathrm{~Hz}$ with an amplitude of $0.005 \mathrm{~V}$.

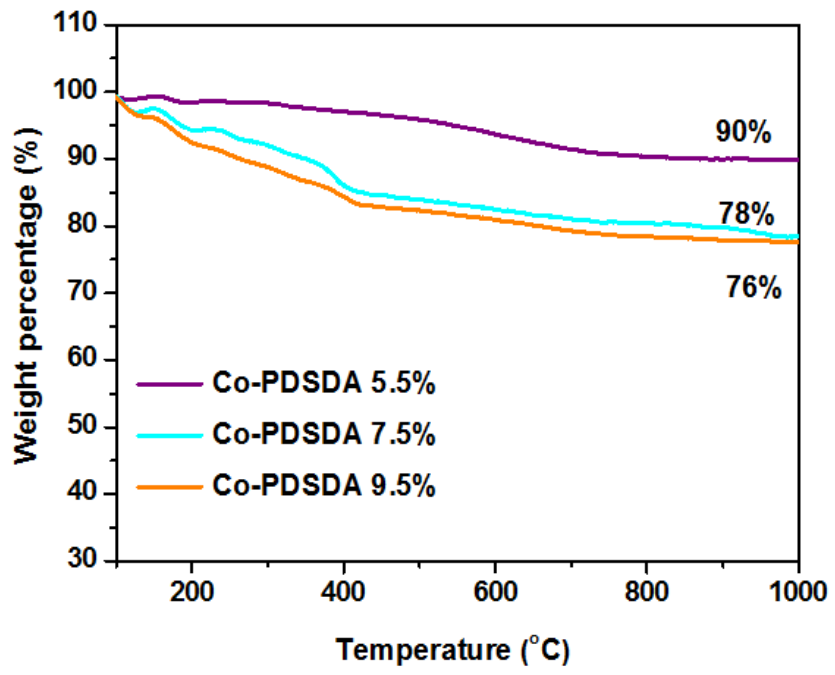

Fig. 1 TGA curves of the Co-PDSDA in a various content ratio of $\mathrm{Co}_{2}(\mathrm{CO})_{8}$ taken at a scanning rate of $10 \mathrm{Kmin}^{-1}$ under an argon atmosphere. 


\section{Results and Discussion}

\subsection{Synthesis of $\mathrm{Co}-\mathrm{Si} / \mathrm{C}$ nanocomposites.}

The $\mathrm{Co}-\mathrm{Si} / \mathrm{C}$ nanocomposites were prepared via pyrolysis of $\mathrm{Co}-$ PDSDA precursor. The schematic routeof cross-linking and pyrolysis of Co-PDSDA to form Co-Si/C nanocomposites is shown in Scheme 1.

For the determination of yield of polymer, thermal gravimetric analysis (TGA) was performed and shown in Fig. 1. With the increase of temperature, the cobalt-coordinated alkynyl groups of PDSDA endured a thermal weight loss in the first region between $100-400{ }^{\circ} \mathrm{C}$, and this loss was attributed to the $\left[-\mathrm{C}-\mathrm{C}-\mathrm{Co}_{2}(\mathrm{CO})_{6}\right]$ groups, which disintegrated into cobalt oxide. The pyrolysis was completed in the second region between $400{ }^{\circ} \mathrm{C}$ and $800{ }^{\circ} \mathrm{C}$ due to the presence of alkynyl groups. After this, the curves nearly levelled off. Therefore, the yield of $\mathrm{Co}-\mathrm{Si} / \mathrm{C} 5.5 \%, \mathrm{Co}-\mathrm{Si} / \mathrm{C} \quad 7.5 \%$ and $\mathrm{Co}-\mathrm{Si} / \mathrm{C} \quad 9.5 \%$ nanocomposites can be estimated to be $90 \%, 78 \%$ and $76 \%$, respectively.

$\mathrm{Co}-\mathrm{Si} / \mathrm{C}$ nanocomposite was prepared via the pyrolysis of $\mathrm{Co}-$ PDSDA precursor coordinated with $\mathrm{Co}_{2}(\mathrm{CO})_{8}$ (Fig. 2a). With the pyrolysis (Fig. 2b), the $\mathrm{Co}-\mathrm{Si} / \mathrm{C}$ nanocomposite showed $\mathrm{CoSi}, \mathrm{Co}_{2} \mathrm{Si}$ and $\mathrm{Si} / \mathrm{C}$ nanocrystals embodied in amorphous carbons with a low degree of graphitic carbon as shownin Fig. 2c. SEM and TEM images clearly revealed the structures of cobalt nanocrystals embodied in amorphous $\mathrm{Si} / \mathrm{C}$ matrix (Fig. 2d,e). The embodied $\mathrm{CoSi}, \mathrm{Co}_{2} \mathrm{Si}$ nanocrystal in Si/C matrix observed in HRTEM image (Fig. 2f) was in good agreement with the lattice spacing of (111), (200) and (220) (hexagonal, PDF\#15-0806) planes of crystal face of Co nanocrystal observed in a SAED pattern (Fig. 2g). A small diffraction peak at $2 \theta=$ $25^{\circ}$ corresponding to $\mathrm{Si} / \mathrm{C}$ was observed in XRD pattern (Fig. 2h), indicative of an amorphous or a low degree of graphitic carbon due to the low content of Co. Cobalt crystal tends to increase the initial lithiation performance, while the amorphous $\mathrm{Si} / \mathrm{C}$ layered structure with the larger surface area reduced the polarization resulted the higher reversible capacity.

SEM was also used to characterize the microstructure and surface morphology of the $\mathrm{Co}-\mathrm{Si} / \mathrm{C}$ nanocomposite. The TGA analyses of Co$\mathrm{Si} / \mathrm{C}$ nanocomposites anode confirmed the high carbon content ratio. In addition, the morphology was highly dependent on the intrinsic content of cobalt crystals. The amorphous structure turned to the crystalline structure with a $9.5 \%$ content of cobalt. Since the $\mathrm{Co}-\mathrm{Si} / \mathrm{C}$ nanocomposites prepared in this study were mixed phases of $\mathrm{CoSi}$, $\mathrm{Co}_{2} \mathrm{Si}$ nanocrystals and $\mathrm{Si} / \mathrm{C}$ carbon layer. Fig. $3 \mathrm{~b}$ shows the diverse morphology for $\mathrm{Co}-\mathrm{Si} / \mathrm{C}$ nanocomposite indicated an amorphous structure with improved crystallinity compared to the Fig. 3a-c. The nanocrystals of cobalt faces were uniformly coordinated with the nanocomposite. High cobalt content in the nanocomposite set the crystalline structure, while the amorphous structure was found with the low addition of cobalt.

HRTEM along and selected area electron diffraction (SAED) were also used to analyse the detailed inner microstructure difference of the nanocomposite. Fig. 4a shows almost an amorphous structure of Co-

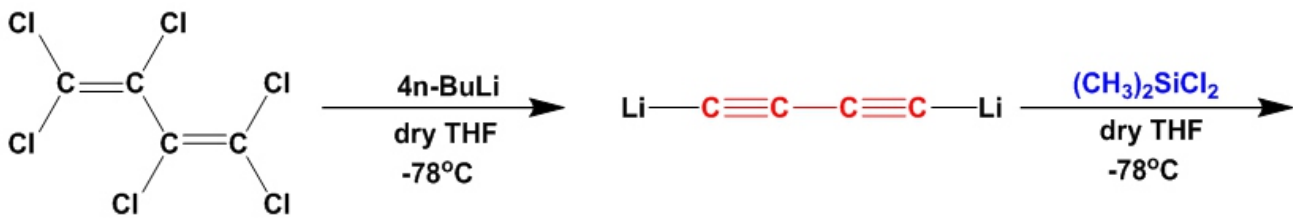
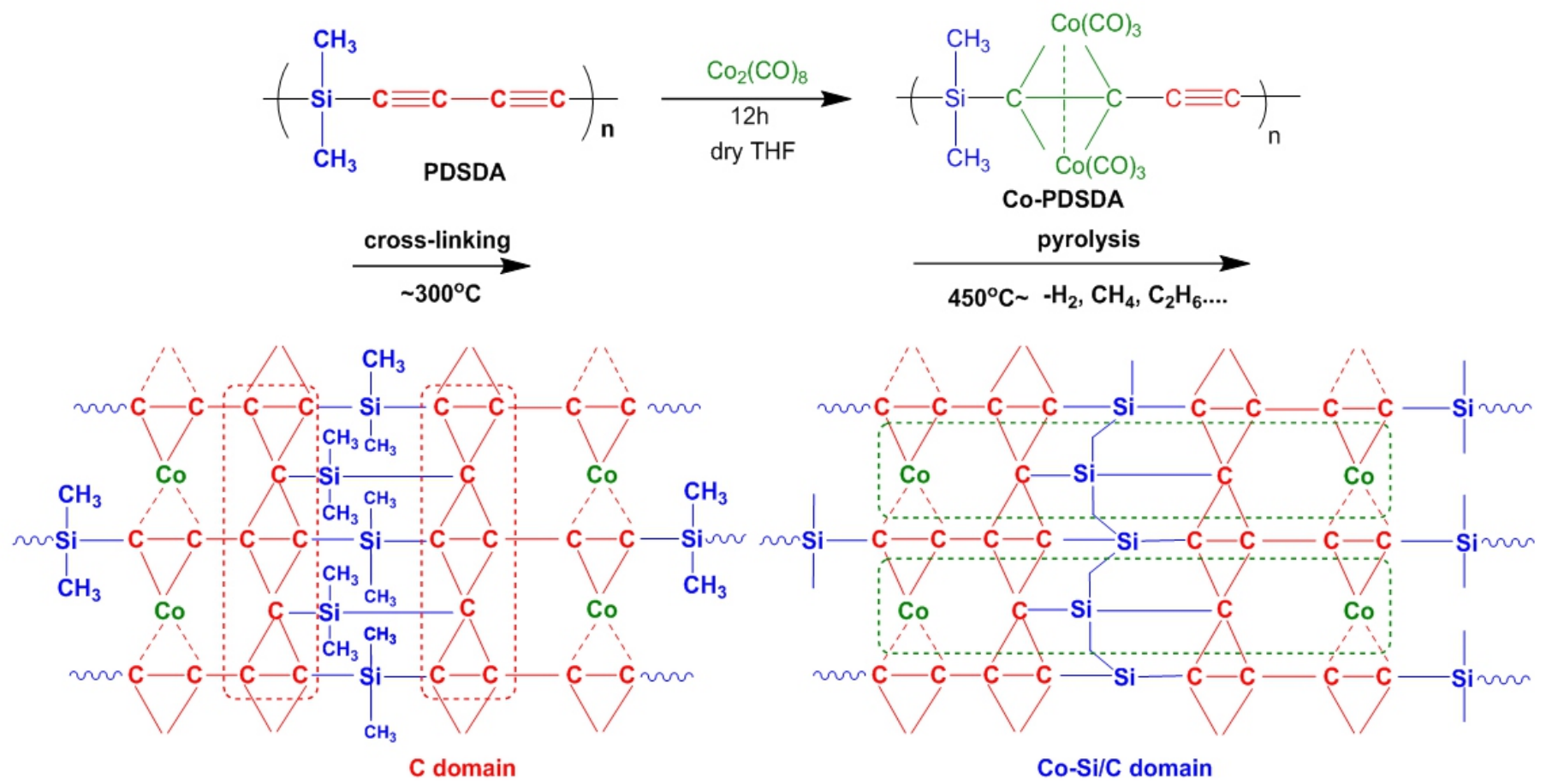

Scheme 1 Synthesis and the cross-linking mechanism of cobalt-coordinated poly(dimethylsilylene)diacetylenes and the formation of $\mathrm{Co}-\mathrm{Si} / \mathrm{C}$ nanocomposite viapyrolysis. 

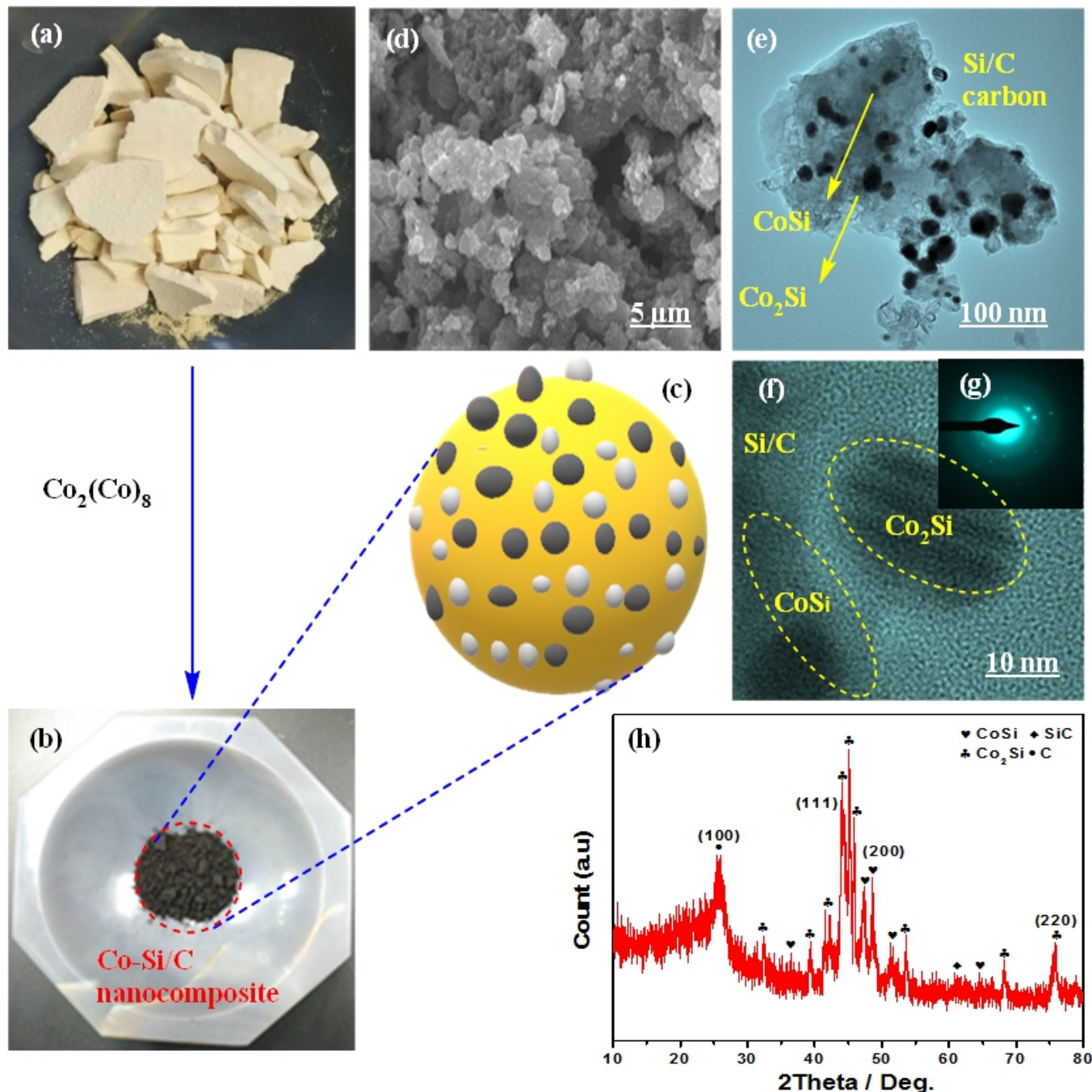

Fig.2 Schematic illustration of Co-Si/C nanocomposite, (a) as-synthesized PDSDA precursor coordinated with dicobaltoctacarbonyl, (b) Co-Si/C nanocomposite, (c) $\mathrm{Co}-\mathrm{Si} / \mathrm{C}$ structure showing $\mathrm{CoSi}, \mathrm{Co}_{2} \mathrm{SiandSiC}$ nanocrystals embodied in amorphous carbon matrix with a low degree of graphitic carbons, (d) SEM image of Co-Si/C, (e) TEM image of Co-Si/C, (f) HRTEM image of Co-Si/C nanocomposite, (g) electron diffraction pattern of Co$\mathrm{Si} / \mathrm{C}$ nanocomposite and (h) XRD pattern of $\mathrm{Co}-\mathrm{Si} / \mathrm{C}$ nanocomposite anode material.
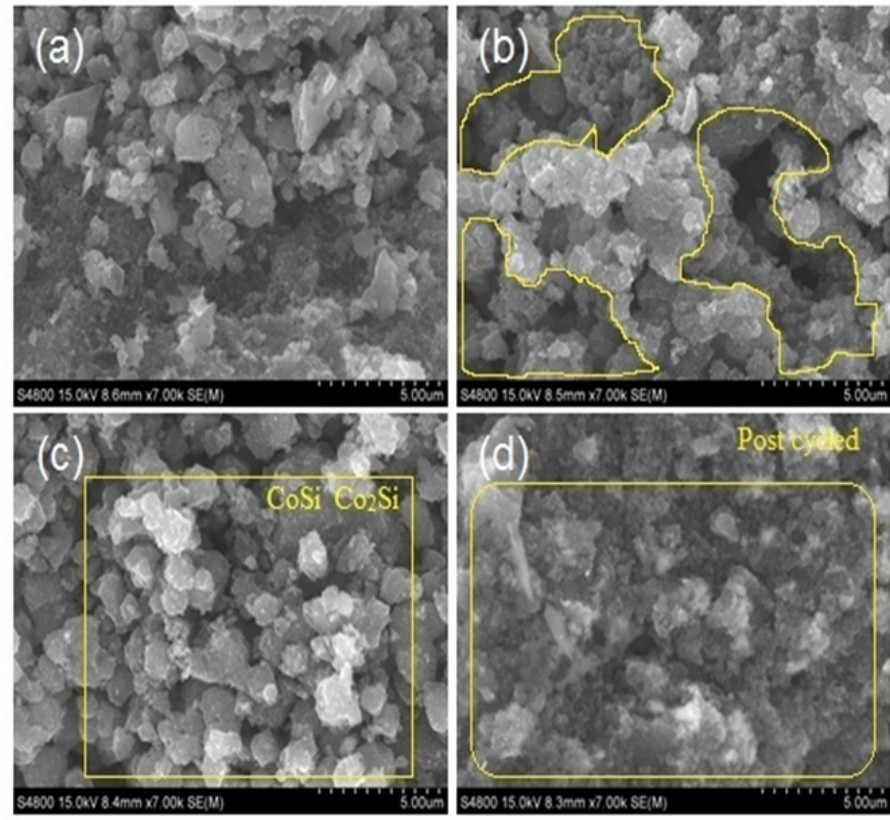

Fig. 3 SEM images of as-prepared Co-Si/C (a) 5.5\% nanocomposite, (b) $7.5 \%$ nanocomposite and (c) $9.5 \%$ nanocomposite before cycling and (d) Co-Si/C 7.5\% nanocomposite post cycled anode. 

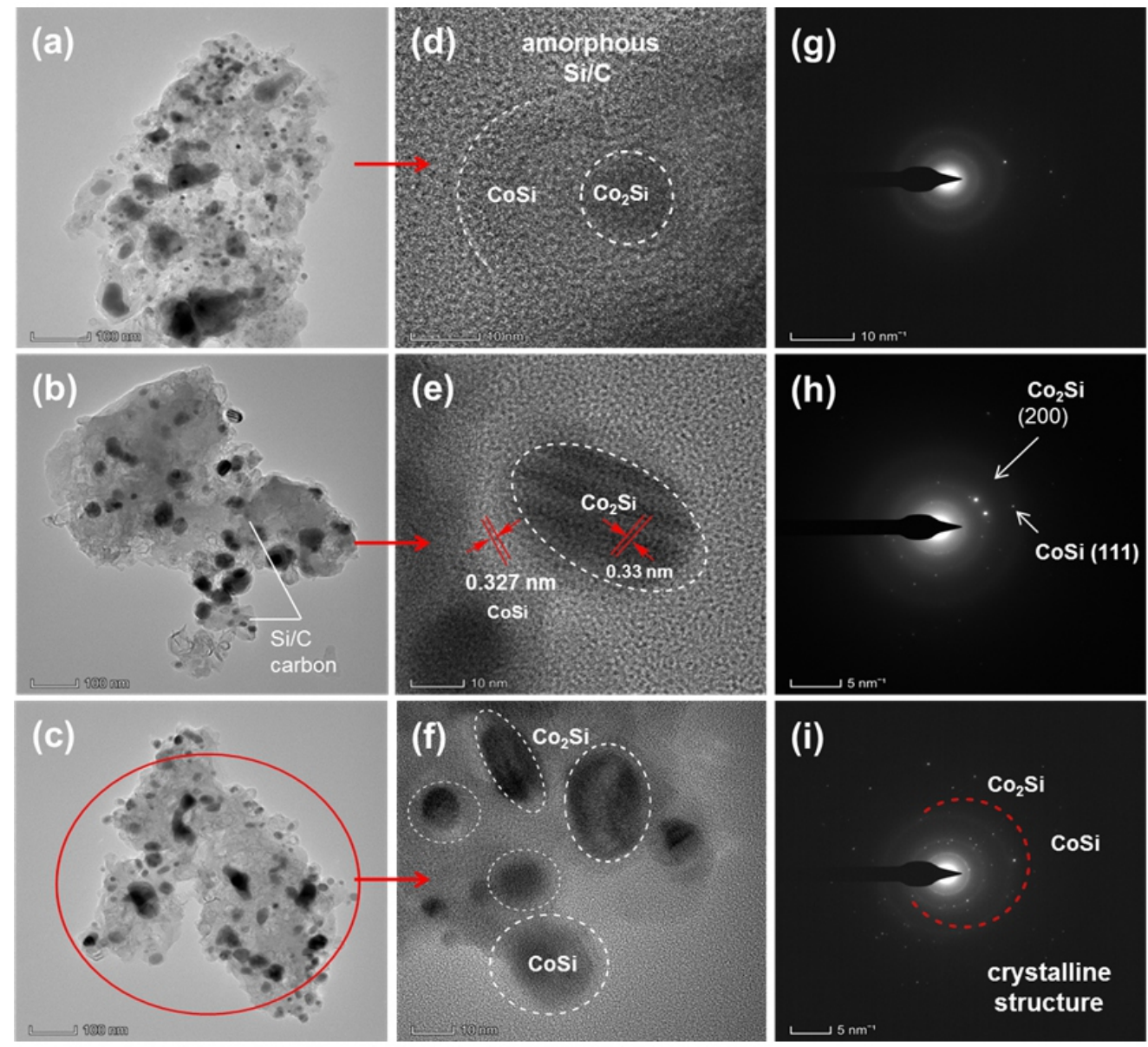

Fig. 4 TEM images of Co-Si/C (a)5.5\%, (b)7.5\% and (c) 9.5\% nanocomposite material and their insert SAED pattern (g, h and i) corresponds to the nature of $\mathrm{Co}-\mathrm{Si} / \mathrm{C} 5.5 \%, \mathrm{Co}-\mathrm{Si} / \mathrm{C} 7.5 \%$ and $\mathrm{Co}-\mathrm{Si} / \mathrm{C} 9.5 \%$ nanocomposite anode, illustrating the changes occurring with addition of the cobalt coordination ratio with polymeric precursor.HRTEM images of Co-Si/C (d) $5.5 \%$, (e) $7.5 \%$ and (f) $9.5 \%$ nanocomposite. The white notes represent the cobalt crystal.

$\mathrm{Si} / \mathrm{C}$ 5.5\%nanocomposite, while Fig. $4 \mathrm{~b}$ reveals the amorphous structure with improved crystallinity of $\mathrm{Co}-\mathrm{Si} / \mathrm{C} 7.5 \%$ nanocomposite. An amorphous $\mathrm{Si} / \mathrm{C}$ layer was formed around the cobalt silicide crystals in Co-Si/C 7.5\% nanocomposite. Fig. 4c presents the crystalline structure of $\mathrm{Co}-\mathrm{Si} / \mathrm{C} 9.5 \%$ nanocomposite. So the overall results confirmed that cobalt was highly coordinated in the composition of $\mathrm{Co}-\mathrm{Si} / \mathrm{C}$ nanocomposite and its higher content ratio promoted the crystalline structure of the nanocomposite. HRTEM images shown in Fig. 4d-f clearly showed the boundaries between cobalt nanoparticles and an amorphous $\mathrm{Si} / \mathrm{C}$ layer. The measured $\mathrm{CoSi}$ and $\mathrm{Co}_{2} \mathrm{Si}$ nanocrystals with inter-planar spacing of 0.327 and $0.330 \mathrm{~nm}$ can be can be detected in Fig. $4 \mathrm{e}$ and enlarged TEM image Fig. 5. All these results clearly demonstrated the improved nanocrystals of cobaltin the SAED pattern of the nanocomposites (Fig. 4g-i).

This nanostructure, reducing the polarization and improving the diffusion rate, resulted in the enhanced electrochemical performance. The EDS mapping images shown in Fig. 6 represented the wellcoordination and uniform distribution of cobalt nanoparticles with carbon, oxygen and silicon elements in the nanocomposite. The improved crystallinity and amorphous $\mathrm{Si} / \mathrm{C}$ structure was consistent with the XRD findings.

The crystallinity with phase purity of the $\mathrm{Co}-\mathrm{Si} / \mathrm{C}$ nanocomposites was analysed via XRD. Fig. 7 displays the XRD patterns of the Co-Si/C

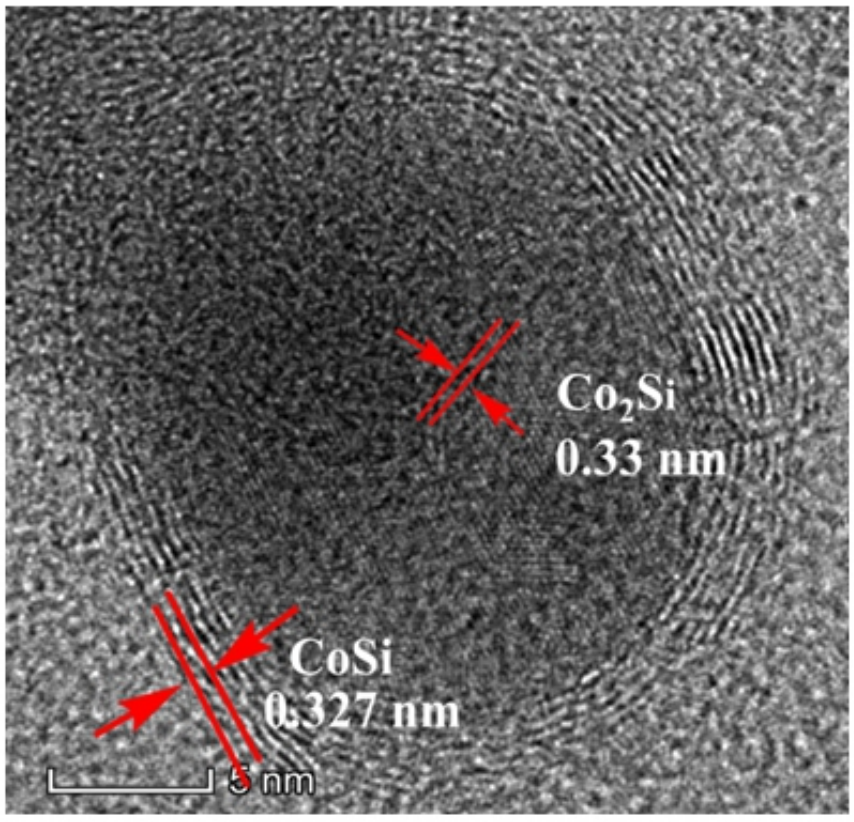

Fig. 5 Enlarged TEM image of $\mathrm{Co}-\mathrm{Si} / \mathrm{C}$ nanocomposite anode material to make $\mathrm{CoSi}$ and $\mathrm{Co}_{2}$ Sinanocrystals clear. 

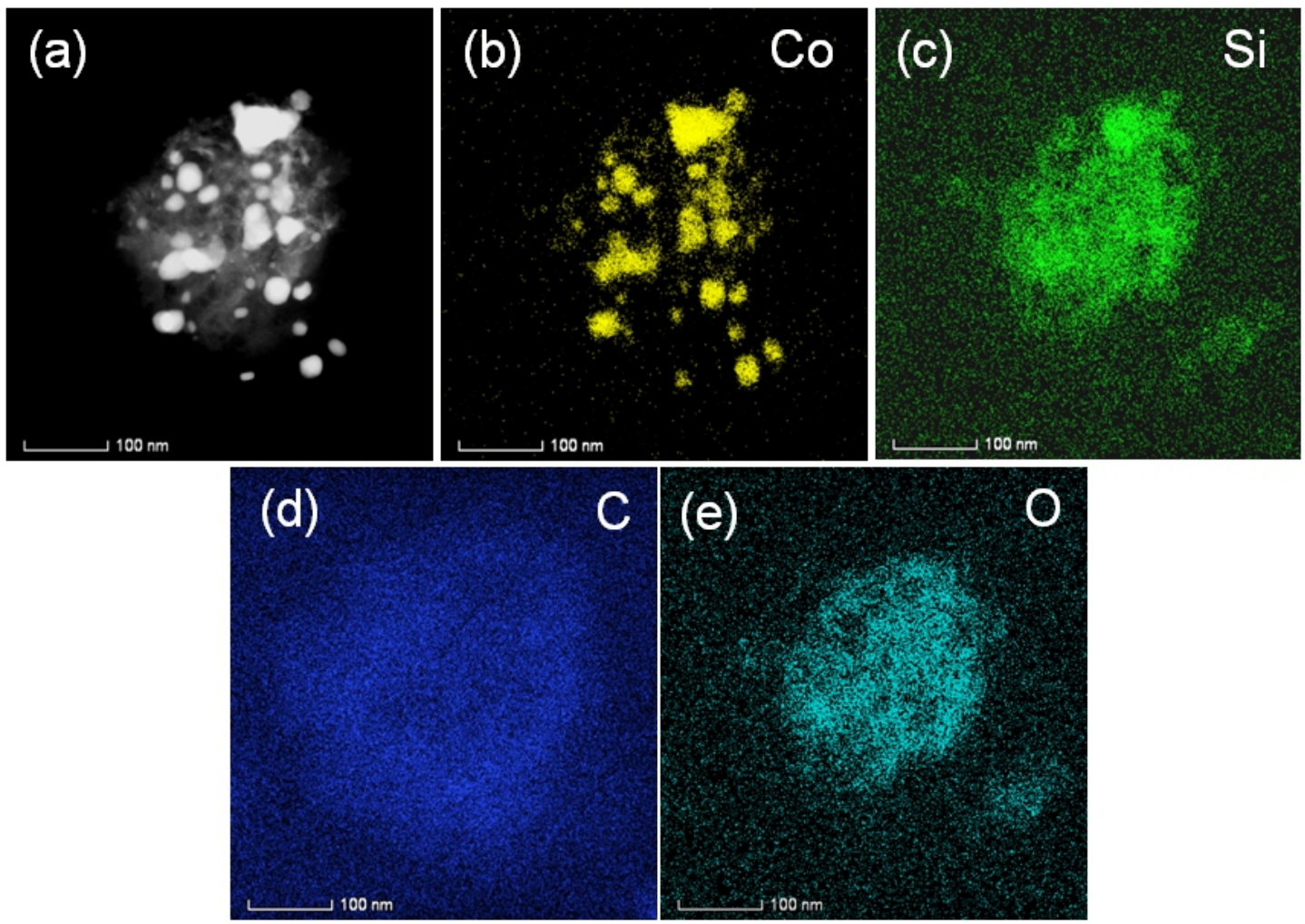

Fig. 6 Elemental maps of $\mathrm{Co}-\mathrm{Si} / \mathrm{C} 7.5 \%$ nanocomposite material for $\mathrm{Co}, \mathrm{Si}, \mathrm{C}$ and $\mathrm{O}$ (b-e). The representative EDS analysis of the selected captured image (a)

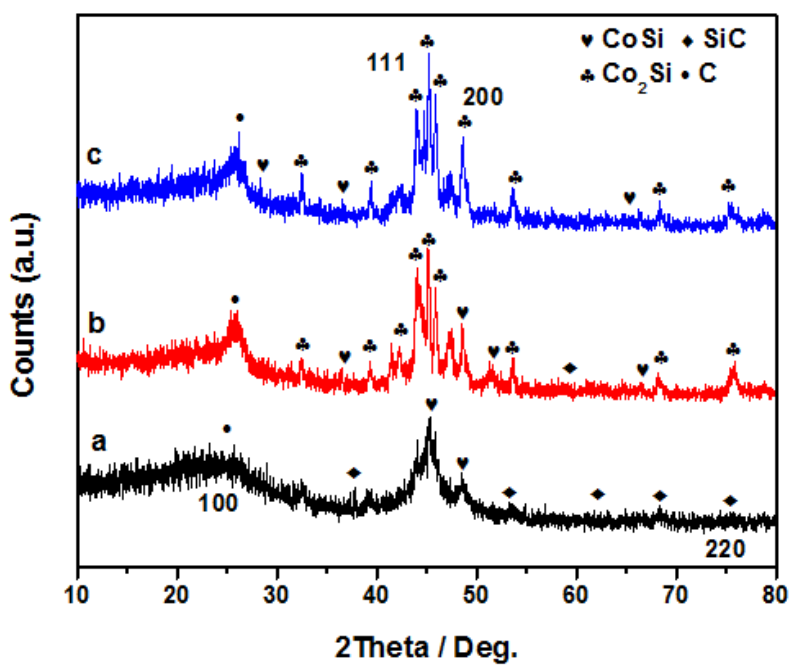

Fig. 7 Powder XRD patterns of $\mathrm{Co}-\mathrm{Si} / \mathrm{C}$ (a) $5.5 \%$, (b) $7.5 \%$ and (c) $9.5 \%$ nanocomposite pyrolyzed at $800{ }^{\circ} \mathrm{C}$.

nanocomposite with $5.5 \%, 7.5 \%$ and $9.5 \%$ of the $\mathrm{Co}_{2}(\mathrm{CO})_{8}$. The broad hump at $2 \theta=25^{\circ}$ was attributed to the amorphous carbons. The obvious peaks with the lattice plane of (100) indicated some graphitic carbons. The main three diffraction peaks presented at $2 \theta=25^{\circ}, 45^{\circ}$ and $48^{\circ}$ corresponded with (100), (111) and (200) (JCPDSNo: 15-0806) were ascribed to the crystal face of cobalt.For the low content of $\mathrm{Co}$, in Co$\mathrm{Si} / \mathrm{C} 5.5 \%$ the intensity of silicon carbide ( $\mathrm{SiC}$ ) crystal peaks decreased and only the Co crystals and amorphous carbons were generated as compared to $\mathrm{Co}-\mathrm{Si} / \mathrm{C} 7.5 \%$ and $\mathrm{Co}-\mathrm{Si} / \mathrm{C} 9.5 \%$ nanocomposite. The Co$\mathrm{Si} / \mathrm{C}$ with a $7.5 \%$ and $9.5 \%$ content of $\mathrm{Co}$ generated crystallinity. The $\mathrm{Co}-\mathrm{Si} / \mathrm{C}$ with $7.5 \%$ generated the cobalt silicide $(\mathrm{CoSi}), \mathrm{Co}_{2} \mathrm{Si}$ nanocrystals and amorphous $\mathrm{Si} / \mathrm{C}$, while the $\mathrm{Co}-\mathrm{Si} / \mathrm{C}$ nanocomposites with $9.5 \%$ form the $\mathrm{CoSi}, \mathrm{Co}_{2} \mathrm{Si}$ nanocrystals and graphite $\mathrm{Si} / \mathrm{C}$. Their peaks observed at $2 \theta=32.5^{\circ}, 39.5^{\circ}, 41.5^{\circ}, 42.8^{\circ}, 47.4^{\circ}, 51.3^{\circ}, 53.6^{\circ}$, $68.39^{\circ}$ and $78.85^{\circ}$ were the same as the simulation of $\mathrm{CoSi}$ and $\mathrm{Co}_{2} \mathrm{Si}$ crystals, (110), (111), (200), (210) and (211) (hexagonal, PDF\#50-1337), respectively.

The XPS survey spectrum was carried out on bulk Co-Si/C nanocomposites powders, which contained the existential form of various chemical states of the entire elements in a wide scan range of 0 to $900 \mathrm{eV}$ as shown in Fig. 8a. The peaks centred at $779 \mathrm{eV}$ and 530 $\mathrm{eV}$, corresponding to the $\mathrm{Co}_{2 \mathrm{p}}$ and $\mathrm{O}_{1 \mathrm{~s}}$, are typical signals to the standard spectra's of cobalt and oxygen. ${ }^{30}$ The peaks at 102, 282.7 and 533 and $779 \mathrm{eV}$ are indexed to the distinctive peaks of Si2p, C1s, O1s and Co2p in $\mathrm{Co}-\mathrm{Si} / \mathrm{C}$ nanocomposites. Since this composite was pyrolyzed at 800 ${ }^{\circ} \mathrm{C}$, it might contain low content of $\mathrm{Si}$ and cobalt. The elemental composition of nanocomposites in Table 1 indicated that the increased content of cobalt from 0.51 to 1.63 and their possible formula is $\mathrm{Si}_{-} \mathrm{C}_{\mathrm{x}}-$ $\mathrm{Co}_{\mathrm{y}}$.

From the high resolution $\mathrm{C}$ 1s spectrum in Fig. 8b, the binding energies at 284.53, 285.53 and $289.13 \mathrm{eV}$ were corresponded to the Si$\mathrm{C}, \mathrm{C}-\mathrm{C}$ and $\mathrm{C}=\mathrm{O}$ groups, ${ }^{31}$ correspondingly. The high resolution peaks at 531.93, 532.6 and $533.72 \mathrm{eV}$ for $\mathrm{O} 1 \mathrm{~s}$ shown in Fig. 8c were ascribed to the Co oxides, $\mathrm{Si}-\mathrm{Ox}$ and $\mathrm{Si}-\mathrm{O}-\mathrm{Si},{ }^{32,33}$ respectively. The distant peak $781.5 \mathrm{eV}$ and $797.82 \mathrm{eV}$ in a HR-spectrum of Co 2p (Fig. 8e) can be corresponded to the binding energies of $\mathrm{Co} 2 \mathrm{p}_{3 / 2}$ and $\mathrm{Co} 2 \mathrm{p}_{1 / 2}$ of $\mathrm{Co}_{2}$ $(\mathrm{Co})_{8}$. This intersection of the advanced binding energy multiple or 
Table 1 Composition of $\mathrm{Co}-\mathrm{Si} / \mathrm{C}$ nanocomposite anode materials.

\begin{tabular}{|c|c|c|c|c|c|c|c|c|}
\hline \multicolumn{3}{|c|}{ Specimens } & \multirow[t]{2}{*}{ Temperature } & \multicolumn{4}{|c|}{ Atom composition $(\%)^{a}$} & \multirow{2}{*}{$\begin{array}{l}\text { Si-C-Co } \\
\text { Formula }\end{array}$} \\
\hline Precursor & $\begin{array}{c}\mathrm{Co}_{2}(\mathrm{CO})_{8} \\
(\mathrm{~mol} \%)\end{array}$ & Nanocomposite & & $\mathrm{C}$ & $\mathrm{Si}$ & Co & $\mathrm{O}^{\mathrm{b}}$ & \\
\hline PDSDA & 5.5 & $\mathrm{Co}-\mathrm{Si} / \mathrm{C}$ & $800^{\circ} \mathrm{C}$ & 70.70 & 9.36 & 0.51 & 19.42 & $\mathrm{Si}_{1} \mathrm{C}_{7.55} \mathrm{Co}_{0.05}$ \\
\hline PDSDA & 7.5 & $\mathrm{Co}-\mathrm{Si} / \mathrm{C}$ & $800^{\circ} \mathrm{C}$ & 73.31 & 6.79 & 1.09 & 18.82 & $\mathrm{Si}_{1} \mathrm{C}_{10.80} \mathrm{Co}_{0.16}$ \\
\hline PDSDA & 9.5 & $\mathrm{Co}-\mathrm{Si} / \mathrm{C}$ & $800^{\circ} \mathrm{C}$ & 73.18 & 6.27 & 1.63 & 18.92 & $\mathrm{Si}_{1} \mathrm{C}_{11.67} \mathrm{Co}_{0.26}$ \\
\hline
\end{tabular}

satellite structures with the cobalt metal peak was because, cobalt requiresthe use of an counter balance for the higher energy background end point, similar to that castoff for nickel. ${ }^{34}$ The peak at $778.3 \mathrm{eV}$ and $780.2 \mathrm{eV}$ were credited to the $\mathrm{Co}$ and $\mathrm{Co}-\mathrm{O}$ bonds. The peaks at 101.67 $\mathrm{eV}$ and $103.36 \mathrm{eV}$ and $104.09 \mathrm{eV}$ in $\mathrm{Si} 2 \mathrm{p}$ spectrum (Fig. 8d) were assigned to the $\mathrm{Si}-\mathrm{C}, \mathrm{SiO}_{2}$ and $\mathrm{C}-\mathrm{C}$ structure in $\mathrm{Co}-\mathrm{Si} / \mathrm{C}$ nanocomposite.

To further examine the surface state of the as-prepared $\mathrm{Co}-\mathrm{Si} / \mathrm{C}$ nanocomposites, the FT-IR measurements were employed. In Fig. 9a, the peaks at $2828 \mathrm{~cm}^{-1}$ and $3418 \mathrm{~cm}^{-1}$ for $\mathrm{Co}-\mathrm{Si} / \mathrm{C} 5.5 \%$ nanocomposite were ascribed to the stretching vibration frequency of alkynyl groups, which vanished in $\mathrm{Co}-\mathrm{Si} / \mathrm{C} 7.5 \%$ and $\mathrm{Co}-\mathrm{Si} / \mathrm{C}$ 9.5\% nanocomposite owing to the increased cobalt ratio. The absorption band at $455 \mathrm{~cm}^{-1}$ and $1070 \mathrm{~cm}^{-1}$ was given to the $\left[-\mathrm{C}-\mathrm{C}-\mathrm{Co}_{2}(\mathrm{CO})_{6}\right]$, ${ }^{35}$ which was intensified with the addition of cobalt ratio. These peaks verified the existence of cobalt in $\mathrm{Co}-\mathrm{Si} / \mathrm{C}$ nanocomposite. The cyclotrimerization of alkynes at $1567.75 \mathrm{~cm}^{-1}$ was correlated with the alkyne trimerization in metal coordination. ${ }^{36,37}$

In order to determine the cobalt nanocrystal and $\mathrm{Si} / \mathrm{C}$ formation, Raman spectroscopy was performed as depicted in Fig. 9b. The two distinct D and $\mathrm{G}$ bandat $1345 \mathrm{~cm}^{-1}$ and $1591 \mathrm{~cm}^{-1}$ showed the disorderinduced vibration and in plane $\mathrm{sp}^{2}$-hybridized of carbon atoms. ${ }^{38,39}$ The $\mathrm{D} / \mathrm{G}$ intensity ratio of $\mathrm{Co}-\mathrm{Si} / \mathrm{C}$ nanocomposite is deceptively increased with the increased content of cobalt value, suggesting that the contribution of cobalt converted the amorphous carbons into crystalline graphitic carbons at $800{ }^{\circ} \mathrm{C}$.

\subsection{Electrochemical performance of $\mathrm{Co}-\mathrm{Si} / \mathrm{C}$ nanocomposites.}

Fig. 10a shows a representativecyclic voltammetry (CV) tested in $0.01 \sim 3.0 \mathrm{~V}$. The two obvious peaks at $0.998 \mathrm{~V}$ and $1.649 \mathrm{~V}$ during the first cathodic scan were linked to the Lithium-ion insertion reactions, the development of solid electrolyte interphase (SEI) film and change of Co-PDSDA to Co-Si/C nanocomposite, respectively. ${ }^{40}$ The 2 nd cathodic scan peak was shifted to $1.835 \mathrm{~V}$ due to the disintegration of SEI layer and stability in the subsequent cycles. This overlapping of the peaks represents an excellent reversibility and high stability. Similarly, the oxidation peaks was detected at the first anodic scan at 0.938 and $1.228 \mathrm{~V}$, which could be attributed to the anodic reaction of cobalt metal. ${ }^{40}$ Notably, the successive anodic curves were also shifted to 0.954 $\mathrm{V}$ at second scan, and almost overlap demonstrating that the Co-Si/C nanocomposite offers good stability towards Li-ion insertion and extraction.

Fig. 10b-d revealed the potential galvanostatic lithiation/delithiation profiles of the $\mathrm{Co}-\mathrm{Si} / \mathrm{C}$ nanocomposites. The first lithiation curve of $\mathrm{Co}-$ $\mathrm{Si} / \mathrm{C} \quad 5.5 \%, \mathrm{Co}-\mathrm{Si} / \mathrm{C} \quad 7.5 \%$ and $\mathrm{Co}-\mathrm{Si} / \mathrm{C} \quad 9.5 \%$ anode successively discloses the initial lithiation capacities to be 1346, 1418.2 and 1410.3
$\mathrm{mAh} \mathrm{g}^{-1}$, correspondingly at $100 \mathrm{~mA} \mathrm{~g}^{-1}$, while the first delithiation curves of $\mathrm{Co}-\mathrm{Si} / \mathrm{C} 5.5 \%, \mathrm{Co}-\mathrm{Si} / \mathrm{C} 7.5 \%$ and $\mathrm{Co}-\mathrm{Si} / \mathrm{C} \quad 9.5 \%$ anode delivered the capacities of $541.7 \mathrm{mAh} \mathrm{g}^{-1}, 1047.9 \mathrm{mAh} \mathrm{g}^{-1}$ and 671.3 $\mathrm{mAh} \mathrm{g}^{-1}$, respectively. The sloping voltage profiles were attributed to the insertion of lithium into cobalt oxide.All the curves show different features in subsequent cycles and presented obvious sloping lines below the potential of 0.1 V.These results are well correlated to the reported study. ${ }^{41,42}$ These assessed performance were better than the reported capacity of bulk $\mathrm{Co}_{3} \mathrm{O}_{4}{ }^{43-46}$

The $\mathrm{Co}-\mathrm{Si} / \mathrm{C} 7.5 \%$ nanocomposite delivered a high first discharge capacity with an ICE of $74 \%$ compared to the specific capacity of CoSi/C 5.5\% (40.24\%) and Co-Si/C 9.5\% (47.60\%) nanocomposites. All these estimated capacities are superior to the theoretical capacity of bulk $\mathrm{Co}_{3} \mathrm{O}_{4}\left(890 \mathrm{mAh} \mathrm{g}^{-1}\right)$. $^{45}$ The irreversible capacity loss (ICL) of $26.11 \%$ was likely originated from the irreversible reaction and interfacial $\mathrm{Li}$ storage and development of the solid electrolyte interface (SEI) layer. ${ }^{42,47}$ The performance of $\mathrm{Co}-\mathrm{Si} / \mathrm{C} 7.5 \%$ nanocomposite with less ICL after a first cycle was owing to its special morphology and structure, which makes this $\mathrm{Co}-\mathrm{Si} / \mathrm{C}$ nanocomposite as a suitable anode for LIBs.

Fig. 10e compare the cycling performance of the $\mathrm{Co}-\mathrm{Si} / \mathrm{C} 5.5 \%$, $\mathrm{Co}-\mathrm{Si} / \mathrm{C} 7.5 \%$ and $\mathrm{Co}-\mathrm{Si} / \mathrm{C} 7.5 \%$ nanocomposites at $100 \mathrm{~mA} \mathrm{~g}^{-1}$ in the voltage range between $0.1-3.0 \mathrm{~V}\left(v \mathrm{Li}^{+} / \mathrm{Li}\right)$. The $\mathrm{Co}-\mathrm{Si} / \mathrm{C} \quad 7.5 \%$ nanocomposite presented an enhanced electrochemical cycling stability at primary cycles with a capability of about $\sim 1105 \mathrm{mAh} \mathrm{g}^{-1}$ compared to $\mathrm{Co}-\mathrm{Si} / \mathrm{C} 5.5 \%\left(\sim 586 \mathrm{mAh} \mathrm{g}^{-1}\right)$ and $\mathrm{Co}-\mathrm{Si} / \mathrm{C}$ 9.5\% ( 690 $\left.\mathrm{mAh} \mathrm{g}^{-1}\right)$ nanocomposites. However, all the anodes retain the constant capacities of $\sim 446 \mathrm{mAh} \mathrm{g}^{-1}, \sim 905 \mathrm{mAh} \mathrm{g}^{-1}$ and $\sim 565 \mathrm{mAh} \mathrm{g}^{-1}$ even after 100 cycles. The $\mathrm{Co}-\mathrm{Si} / \mathrm{C}$ 7.5\% nanocomposite displayed high electrochemical performance with dramatically increased Coulombic efficiency reaching over $99 \%$ after 100 cycles. Our achieved capacities are greater than the reported theoretical values of commercial available graphite $\left(\sim 372 \mathrm{mAh} \mathrm{g}^{-1}\right)$. $^{48}$ The capacity's fading of $0.23 \%, 0.19 \%$, and $0.18 \%$ per cycle in comparison with the initial cycles were credited to the formation of SEI passivating film at initial cycles, which induced the irreparable capacity. The irreparable capacity loss of the designed anodes were better than the reported results. ${ }^{49}$

\subsection{Capacities and prolong cycling at high current density.}

To further prove the suitability for practical application, $\mathrm{Co}-\mathrm{Si} / \mathrm{C} 7.5 \%$ nanocomposite was tested on prolong cycling at $500 \mathrm{~mA} \mathrm{~g}^{-1}$ is showing in Fig. 11a. The Co-Si/C 7.5\% nanocomposite also exhibits a superior stable specific capacity of $\sim 540 \mathrm{mAh} \mathrm{g}^{-1}$ after $1000^{\text {th }}$ cycle with an average coulombic efficiency of $99 \%$, greater than the reported capacity of CPs designed anodes (Table 2). ${ }^{50-53}$ 

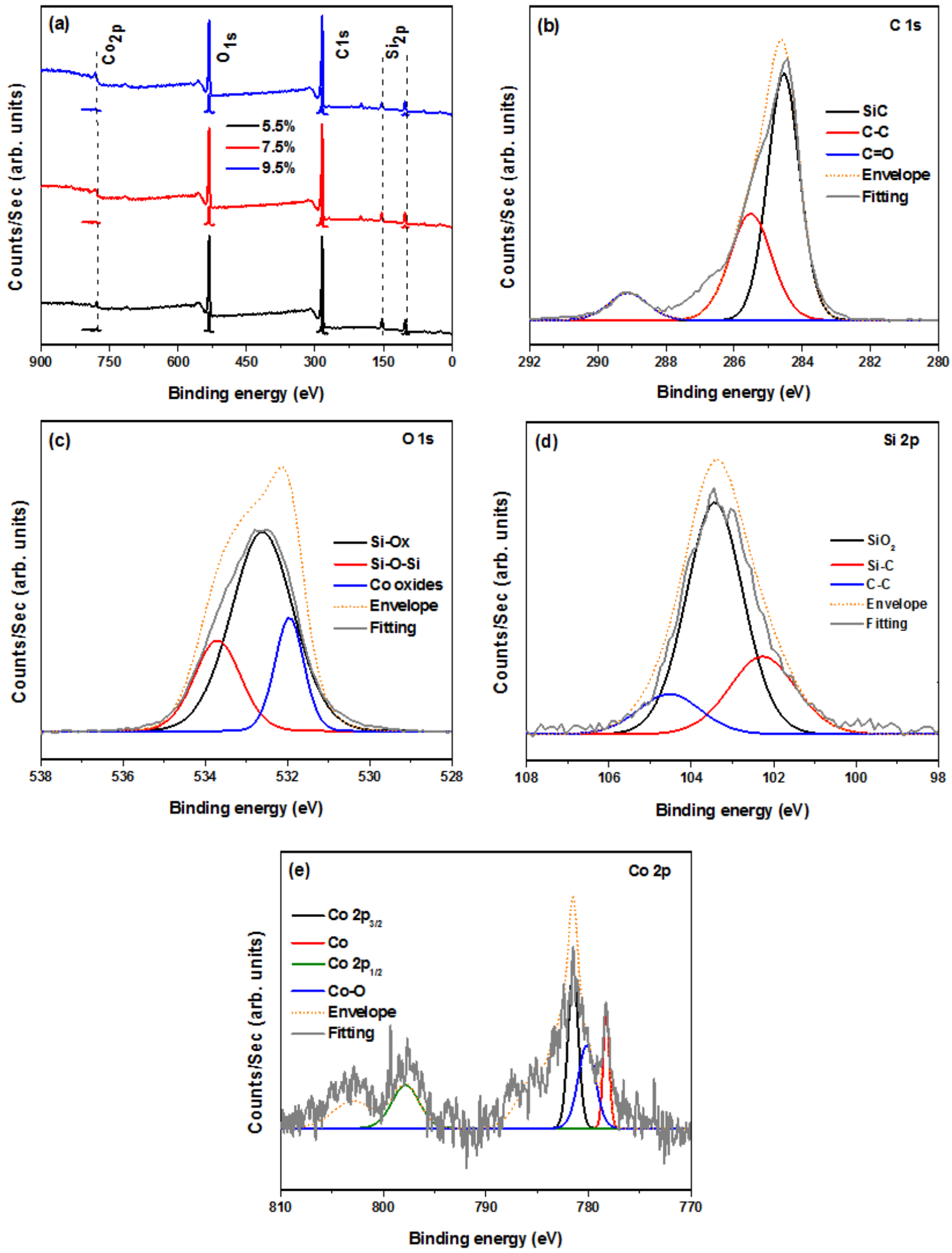

Fig. 8 XPS survey spectra of Co-Si/C nanocomposites anode material (a),High-resolution XPS spectra of Co-Si/C 7.5\% nanocomposite anode from C 1s (b), O 1s (c), Si 2p (d) and Co 2p (e) peaks, respectively. 
To better understand the benefit of using $\mathrm{Co}-\mathrm{Si} / \mathrm{C}$ nanocomposites, the rate capability behaviour of designed anodes was evaluated (Fig. 11b). All the Co-Si/C nanocomposites show a high performance at a low current density; however, the performance decreased with the increased current density. $\mathrm{Co}-\mathrm{Si} / \mathrm{C} \quad 7.5 \%$ nanocomposite delivered outstanding reversible capacities of $\sim 897 \mathrm{mAh} \mathrm{g}^{-1}, \sim 758 \mathrm{mAh} \mathrm{g}^{-1}, \sim 632$ $\mathrm{mAh} \mathrm{g}^{-1}, \sim 540 \mathrm{mAh} \mathrm{g}^{-1}$ and $\sim 431 \mathrm{mAh} \mathrm{g}^{-1}$ at current rates of $100 \mathrm{~mA} \mathrm{~g}$ ', $200 \mathrm{~mA} \mathrm{~g}^{-1}, 400 \mathrm{~mA} \mathrm{~g}^{-1}, 500 \mathrm{~mA} \mathrm{~g}^{-1}$ and $1000 \mathrm{~mA} \mathrm{~g}^{-1}$, respectively.

Fascinatingly, even at $1000 \mathrm{~mA} \mathrm{~g}^{-1}$, a reversible capacity of $\sim 430$ $\mathrm{mAh} \mathrm{g}^{-1}$ was recorded with an average CE of $98 \%$. When the current density was again brought down to $100 \mathrm{mAg}^{-1}$, its wiftly recovered to the capacity of $\sim 875 \mathrm{mAh} \mathrm{g}^{-1}$ after 60 cycles. This significant capacity set a new record for nanocomposite materials derived from polymer precursors. Thus, Co-Si/C 7.5\% nanocomposite keeps the stable subsequent cycles and showed a good rate capability at a fast Li-ions insertion/extraction. Secondly, low capacity of $\mathrm{Co}-\mathrm{Si} / \mathrm{C} 5.5 \%$ and $\mathrm{Co}-$ $\mathrm{Si} / \mathrm{C}$ 9.5\% nanocomposites were attributed to their structure, which had a small and low electron transfer rate for lithium storage properties due to the less active site. The increased content of the cobalt ratio improves the crystalline structure and decreased the surface area. Poizot et al. ${ }^{54}$ described that each metal has specific size which contributed better cycling performance. The decreased capacity of $\mathrm{Co}-\mathrm{Si} / \mathrm{C} 9.5 \%$ nanocomposite was due to the crystalline nature of cobalt structure that decreased the surface area of the nanocomposite, causing the high polarization and less Li-ion diffusion, which impacts the electrochemical performance.

The improved electrochemical characteristics described herein can be correlated to the structural integration of $\mathrm{Co}-\mathrm{Si} / \mathrm{C} \quad 7.5 \%$ nanocomposite material, which has a greaternumber of transferred electrons and the fast conversion reaction between lithium ions and $\mathrm{Co}$ $\mathrm{Si} / \mathrm{C}$ nanocomposite. ${ }^{54}$ The amorphous structure in the $\mathrm{Co}-\mathrm{Si} / \mathrm{C}$ nanocomposite not only stables the lithiation process, but also increases the reversible capacity to absorb the lithium ions. Furthermore, the crystalline structure of $\mathrm{Co}-\mathrm{Si} / \mathrm{C}$ nanocomposite maintains the embodied nanocrystals of $\mathrm{CoSi}$ and $\mathrm{Co}_{2} \mathrm{Si}$. These nanocrystals initiate the decomposition of lithium oxide and enhance the excellent performance. Most importantly, the amorphous nanomaterials provided the larger surface area for Li-ion diffusion and shorten the pathway to reach Liions towards an electrolyte during insertion/extraction reaction. ${ }^{55-57}$ It might be act as a reservoir for storage of $\mathrm{Li}$-ions and also carbon coating accommodates the pulverization of silicon during $\mathrm{Li}^{+}$extraction. The morphological stability was established through scanning electron microscope images of the post-cycled $\mathrm{Co}-\mathrm{Si} / \mathrm{C} 7.5 \%$ nanocomposite anode material shown in Fig. 3d.
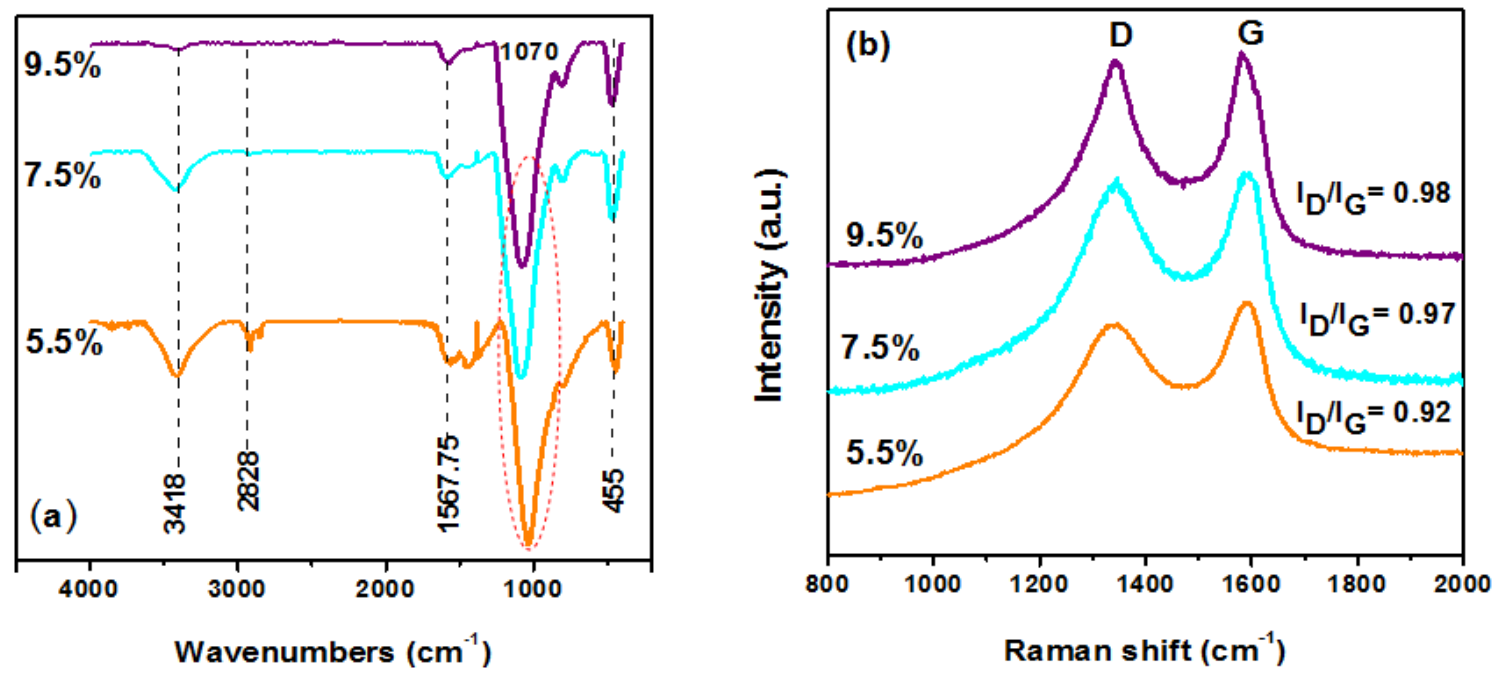

Fig. 9 (a) FTIR and (b) Raman spectroscopy for the Co-Si/C nanocomposite with various content of cobalt, illustrating the changes occurring with the addition of cobalt content coordination with polymeric precursor.

Table 2 The comparison of the different electrodes for Lithium ion batteries performance.

\begin{tabular}{|c|c|c|c|c|}
\hline Samples & Current density/mAh $\mathrm{g}^{-1}$ & Capacity/mA h g ${ }^{-1}$ & $n$th cycle & References \\
\hline $\mathrm{CoC}_{6} \mathrm{H}_{2} \mathrm{O}_{5}\left(\mathrm{H}_{2} \mathrm{O}\right)_{2}$ & 95 & 549.8 & 100 & 50 \\
\hline $\mathrm{CoC}_{6} \mathrm{H}_{2} \mathrm{O}_{5}\left(\mathrm{H}_{2} \mathrm{O}\right)_{2}$ & 1250 & 513.4 & 499 & 50 \\
\hline Hierarchical $\mathrm{Co}_{1{ }^{-} \mathrm{x}} \mathrm{S}$ & 100 & 320 & 50 & 51 \\
\hline $\mathrm{NC} / \mathrm{CoS}_{2}$ & 100 & 560 & 50 & 52 \\
\hline $\mathrm{V}^{\mathrm{IV}}(\mathrm{O})(\mathrm{bdc})[\mathrm{MIL}-47]$ & 10 & 82 & 50 & 53 \\
\hline $\mathrm{Co}-\mathrm{Si} / \mathrm{C}$ nanocomposite & 100 & 905 & 100 & This work \\
\hline
\end{tabular}



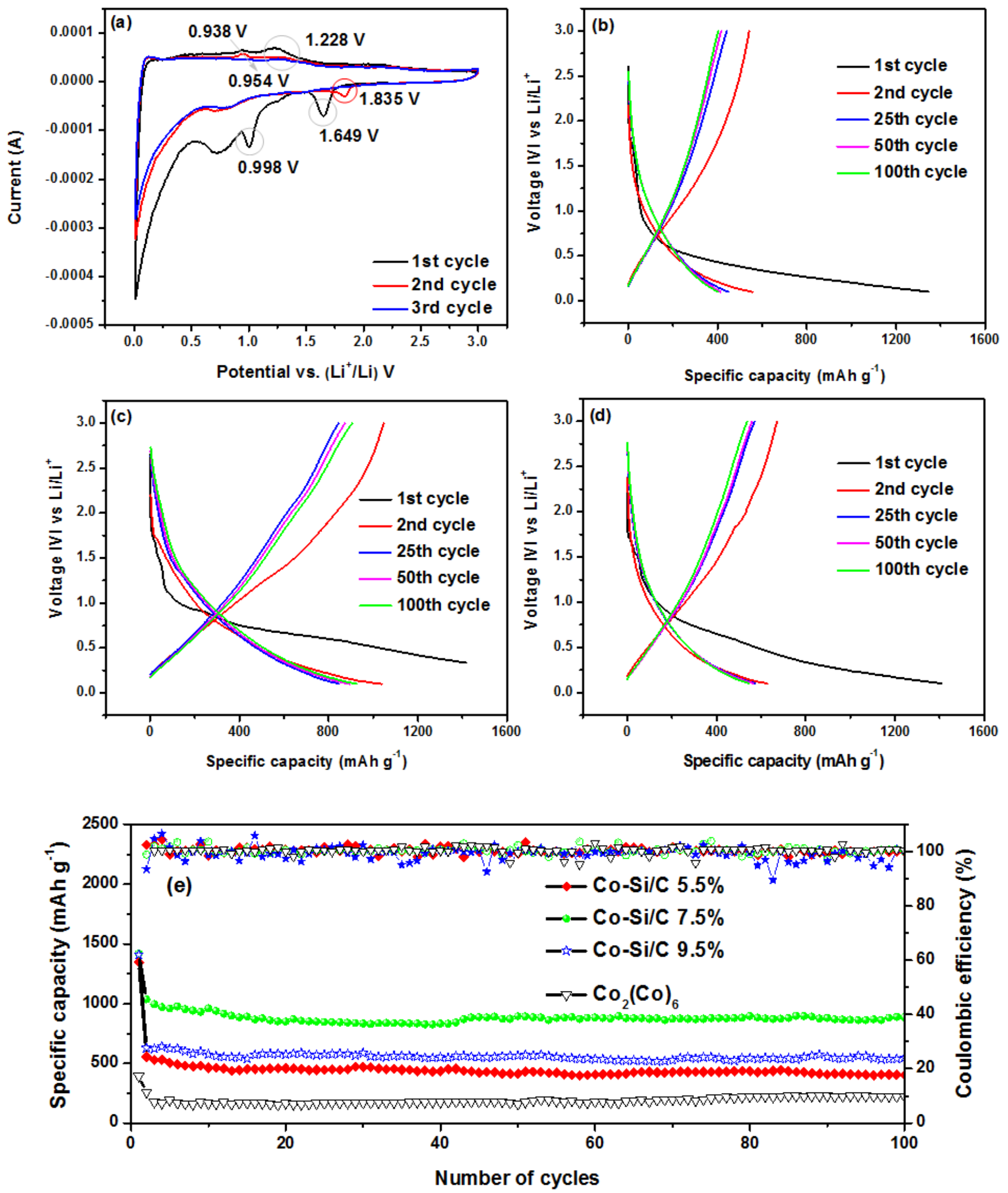

Fig. 10 Cyclic voltammetry of Co-Si/C nanocomposite (a), capacity potential charge/discharge curves of the Co-Si/C nanocomposite (b) 5.5\%, (c) 7.5\% and (d) $9.5 \%$ nanocomposite and (e) cyclic performances of as-prepared $\mathrm{Co}-\mathrm{Si} / \mathrm{C}$ nanocomposite anode recorded at the current rate of $0.1 \mathrm{~A} \mathrm{~g}^{-1}$. 


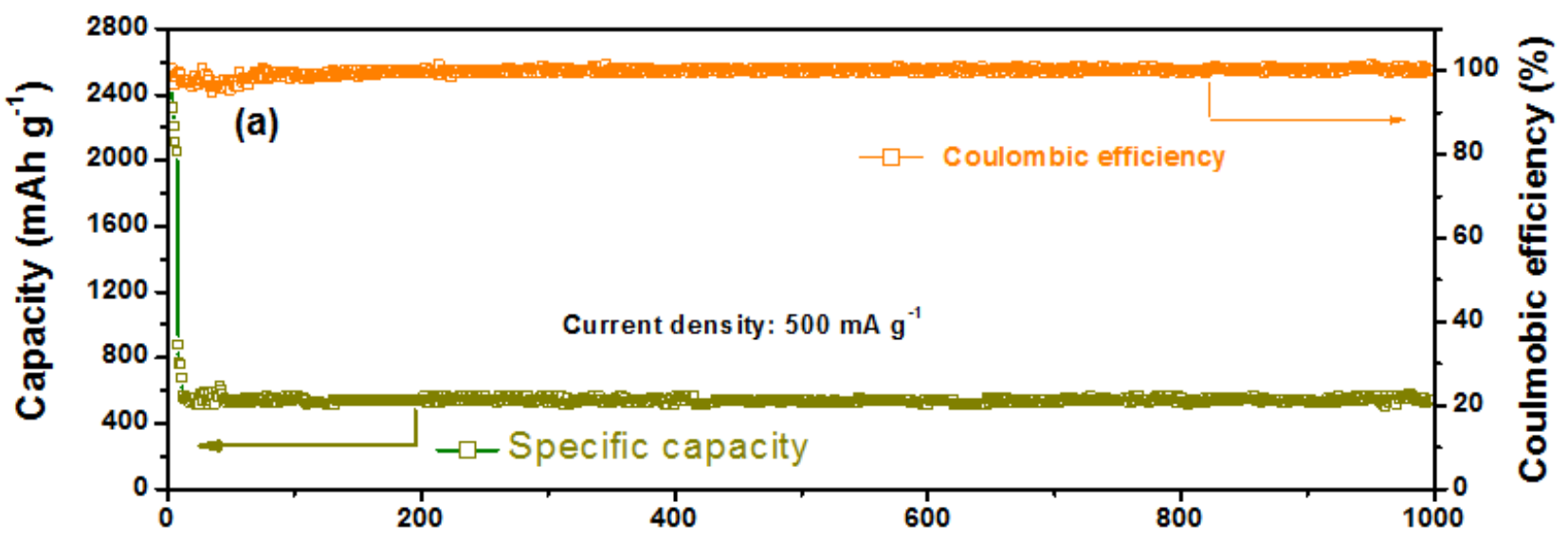

Number of cycles
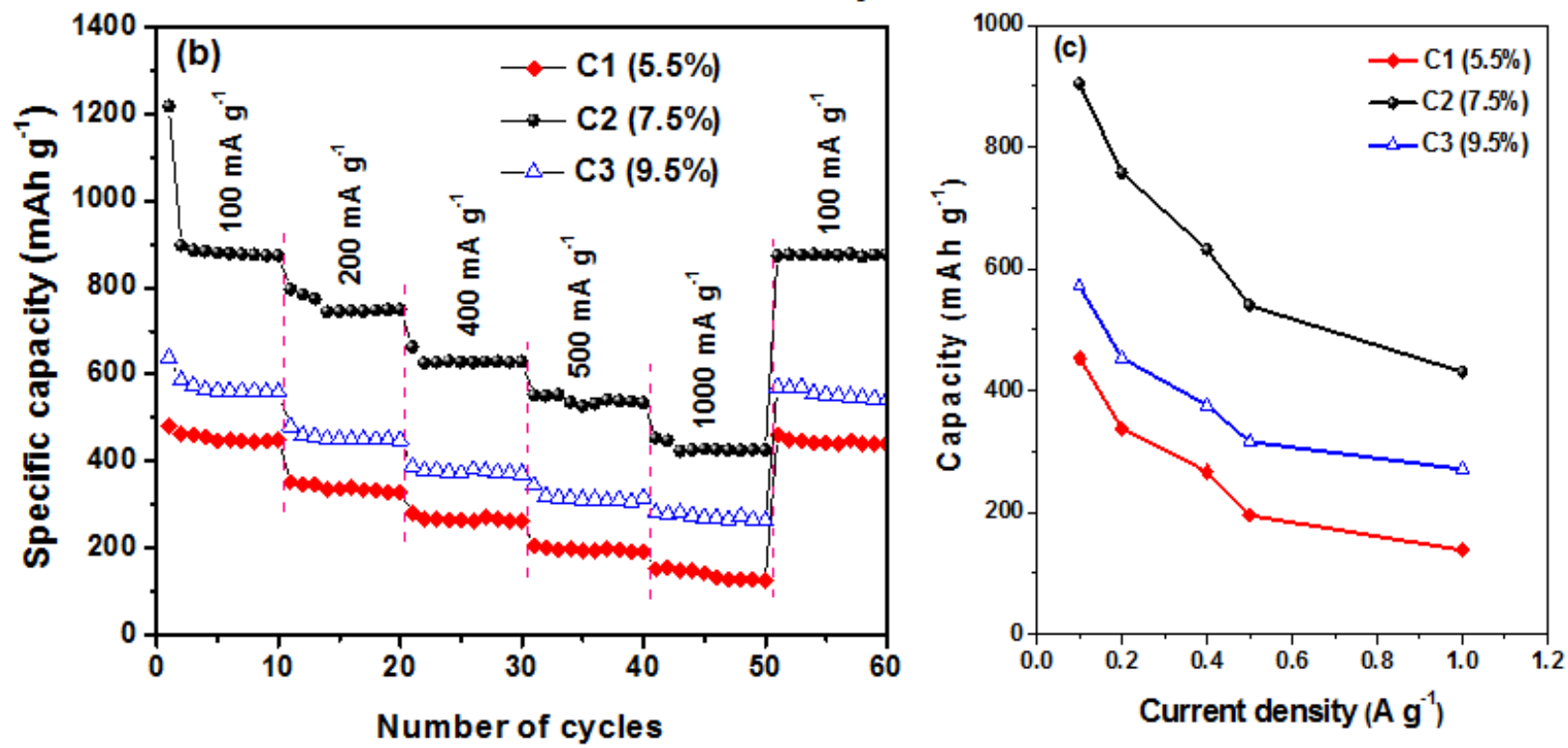

Fig. 11 (a) Long term electrochemical performances (capacity and efficiency set against cycle number), (b) Rate performance of as-prepared Co-Si/C nanocomposites when cycled asymmetrically, and (c) specific capacity retention capability values at applied increasing current densities of Co-Si/C $7.5 \%$ nanocomposite anode.

The $\mathrm{Co}-\mathrm{Si} / \mathrm{C} 7.5 \%$ nanocomposite was agglomerated compared to its initial uniform dispersed state owing to the continual volume variations after 100 cycles. There was no clear sign of cracking and pulverization, which endorses that structural stability in the continuous lithiation and delithiation progression. Thus, the structure of $\mathrm{Co}-\mathrm{Si} / \mathrm{C}$ nanocomposite remains stable.Cobalt crystals maintain intact with the amorphous $\mathrm{Si} / \mathrm{C}$ layer, resulting in the stability of the $\mathrm{Co}-\mathrm{Si} / \mathrm{C}$ nanocomposite. Considering the demand of long cycling stability and rate capacity, an improved crystallinity of $\mathrm{Co}-\mathrm{Si} / \mathrm{C}$ nanocomposite was essential as potential anode materials.

Electrochemical impedance spectra (EIS) of the $\mathrm{Co}-\mathrm{Si} / \mathrm{C}$ nanocomposites were carried via a half-cell with lithium metal. Nyquist plots at the open circuit voltage in a frequency between $10^{5}-0.01 \mathrm{~Hz}$ with an amplitude of $0.005 \mathrm{~V}$ are presented in Fig. 12. We observed a depressed semicircle at high to medium frequency range, which was consisted to charge transfer resistance $\left(R_{c t}\right)$ and solid electrolyte interface.

The inclined slope lines at low frequencies were correlated with the ion diffusion resistance inside the anode, called as the Warburg impedance. It can be observed that the $\mathrm{Co}-\mathrm{Si} / \mathrm{C} 7.5 \%$ nanocomposite

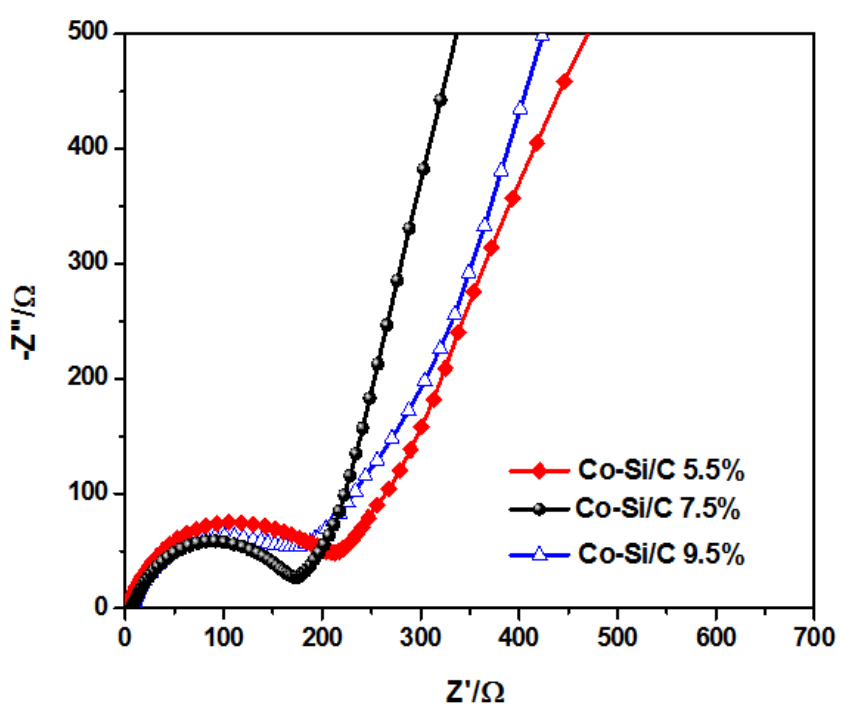

Fig. 12 Nyquist plots of the $\mathrm{AC}$ impedance spectra for $\mathrm{Co}-\mathrm{Si} / \mathrm{C}$ nanocomposites. 
demonstrated a smaller depressed semicircle compared to $\mathrm{Co}-\mathrm{Si} / \mathrm{C} 5.5 \%$ andCo-Si/C 9.5\% nanocomposites, which confirmed a smaller electrochemical resistance in the $\mathrm{Co}-\mathrm{Si} / \mathrm{C} 7.5 \%$ nanocomposite. The observed $\mathrm{R}_{\mathrm{ct}}$ value of $\mathrm{Co}-\mathrm{Si} / \mathrm{C} 7.5 \%$ anode was $168 \Omega$, while $\mathrm{Co}-\mathrm{Si} / \mathrm{C}$ $5.5 \%$ and $\mathrm{Co}-\mathrm{Si} / \mathrm{C} 9.5 \%$ anodes presented $\mathrm{R}_{\mathrm{ct}}$ values of about $213 \Omega$ and $173 \Omega$, respectively. This value implying the much easier electron transferduring lithiation and delithiation. Moreover, it suggested that the Co-Si/C 7.5\% nanocomposite had a high electrical conductivity, which could be ascribed to the continuous carbon network. ${ }^{58}$

\section{Conclusion}

The Co-Si/C nanocomposite was prepared via pyrolysis of Co-PDSDA as anode material for LIBs. An amorphous $\mathrm{Si} / \mathrm{C}$ layer had more active sites (phase) that binds the Li-ions and acted as ion collector resulting enhanced reversible capacities, while the improved crystalline structural stability enhanced the Li-ion intercalation. The $\mathrm{Co}-\mathrm{Si} / \mathrm{C}$ nanocomposite anodes exhibited promising superior cyclic properties and kept a high discharge capacity of about $1105 \mathrm{mAh} \mathrm{g}^{-1}$. They maintained a specific capacity of $905 \mathrm{mAh} \mathrm{g}^{-1}$ after 100 cycles at $100 \mathrm{~mA} \mathrm{~g}^{-1}$ with an average coulombic efficiency of $81.9 \%$ and a high specific capacity of $540 \mathrm{mAh}$ $\mathrm{g}^{-1}$ after 1000 cycles at $500 \mathrm{~mA} \mathrm{~g}^{-1}$ with an average coulombic efficiency of $99 \%$. This is the first-reported study of $\mathrm{Co}-\mathrm{Si} / \mathrm{C}$ nanocomposite as a promising next generation anode for LIBs. These findings provide a promising method, which could be prolonged to additional $\mathrm{MO}_{\mathrm{x}}$ with PDSDA precursor ceramic anode, to improve the electrochemical performance ofLIBs.

\section{Notes}

The authors declare no competing financial interest.

\section{Acknowledgements}

This research is supported by the Natural Science Basic Research Plan in Shaanxi Province of China (2018JC-008, Distinguished Young Scholar), the Shaanxi Province Key Research and Development Plan for Industry Innovation Chain (Cluster) (2018ZDCXL-GY-09-07). M.I. thanks the support of Chinese Scholarship Council (CSC, 2015GXZ039) Ph.D. Scholarship. B.X. thanks the support of the Engineering and Physical Sciences Research Council (EPSRC) grant from UK-EP/N007921/1.

\section{References}

1. D. Larcher and J. M. Tarascon, Nat. Chem., 2015, 7, 19-29.

2. B. Dunn, H. Kamath and J. M. Tarascon, Science, 2011, 334, 928-935.

3. S. L. Chou, J. Z. Wang, H. K. Liu and S. X. Dou, J. Power Sources, 2008, 182, 359-364

4. Y. P. Wu, E. Rahm and R. Holze, J. Power Sources, 2003, 114, 228-236.

5. P. G. Bruce, S. A. Freunberger, L. J. Hardwick and J. M. Tarascon, Nat. Mater, 2012, 11, 19-29.

6. Y. M. Chen, X. Y. Yu, Z. Li, U. Paik and X. W. D. Lou, Sci. Adv., 2016, 2, 1600021

7. Y. Zhao, X. Li, B. Yan, D. Xiong, D. Li, S. Lawes and X. Sun, Adv. Energy Mater., 2016, 6, 1502175.

8. B. Huang, X. Li, Y. Pei, S. Li, X. Cao, R. C. Massé, G. Cao, Small, 2016, 12, 1945-1955.

9. Z. S. Wu, W. Ren, L. Wen, L. Gao, J. Zhao, Z. Chen and G. Zhou, F. Li, H. M. Cheng, ACS Nano, 2010, 4, 3187-3194.

10. X. Zhu, Y. Zhu, S. Murali, M. D. Stoller and R. S. Ru off, ACS Nano, 2011, 5, 3333-3338.

11. L. Zhang, H. B. Wu, S. Madhavi, H. H. Hng and X. W. Lou, J. Am. Chem. Soc., 2012, 134, 17388-17391.

12. X. Zhou, Z. Dai, S. Liu, J. Bao and Y. G. Guo, Adv. Mater., 2014, 26, 3943-
3949.

13. S. Zhu, J. Li, X. Deng, C. He, E. Liu, F. He, C. Shi and N. Zhao, Adv. Funct Mater., 2017, 27, 1605017.

14. S. R. Batten, N. R. Champness, X. M. Chen, J. Garcia-Martinez, S. Kitagawa L. Ohrstrom, M.O. Keeffe, M. P. Suh and J. Reedijk, Pure Appl. Chem., 2013, 85, 1715-1724.

15. M. Armand, S. Grugeon, H. Vezin, S. Laruelle, P. Ribiere, P. Poizot and J. M. Tarascon, Nat. Mater, 2009, 8, 120-125.

16. W. Walker, S. Grugeon, H. Vezin, S. Laruelle, M. Armand, J. M. Tarascon and F. Wudl, Electrochem. Commun., 2010, 12, 1348-1351.

17. H. Fei, Z. Li and X. Liu, J. Alloys Compd., 2015, 640, 118-121.

18. D. Asakura, C. H. Li, Y. Mizuno, M. Okubo, H. Zhou and D. R. Talham, J. Am. Chem. Soc., 2013, 135, 2793-2799.

19. C. Zhang, H. Wu, Z. Guo and X. D. Lou, Electrochem. Commun., 2012, 20, 7-12.

20. Y. Zhou, D. Yan, H. Xu, S. Liu, J. Yang and Y. Qian, Nanoscale, 2015, 7, 3520-3525.

21. P. C. Cheng, W. C. Lin, F. S. Tseng, C. C. Kao, T. G. Chang, D. S. Raja, W. R. Liu and C. H. Lin, Dalton Trans., 2013, 42, 2765-2772.

22. Q. Liu, L. Yu, Y. Wang, Y. Ji, J. Horvat, M. L. Cheng, X. Jia and G. Wang, Inorg. Chem., 2013, 52, 2817-2822.

23. C. Shi, Q. Xia, X. Xue, Q. Liu and H. J. Liu, RSC Adv., 2016, 6, 4442-4447.

24. L. Guo, H. X. Zhang, X. Y. Fan and D. L. Li, Inorg. Chim. Acta, 2013, 393, $10-14$.

25. R. H. Zeng, X. P. Li, Y. C. Qiu, W. S. Li, J. Yi, D. S. Lu, C. L. Tan and M. Q. Xu, Electrochem. Commun., 2010, 12, 1253-1256.

26. S. Chen, W. Yeoh, Q. Liu and G. Wang, Carbon, 2012, 50, 4557-4565.

27. Y. Wang, Y. Wang, E. Hosono, K. Wang and H. Zhou, Angew. Chem. Int. Ed., 2008, 47, 7461-7465.

28. R. J. P. Corriu, N. Devylder, C. Guérin, B. Henner and A. Jean, Organometallics, 1994, 13, 3194-3202

29. C. Luo, W. Duan, X. Yin and J. Kong, J. Phys. Chem. C, 2016, 120, 1872118732 .

30. C. L. Liao, Y.H. Lee, S. T. Chang and K. Z. Fung, J. Power Sources, 2006, 158, 1379-1385.

31. Y. Song, L. He, X. Zhang, F. Liu, N. Tian, Y. Tang and J. Kong, J. Phys. Chem. C, 2017, 121, 24774-24785

32. C. Luo, T. Jiao, J. Gu, Y. Tang and J. Kong, ACS Appl. Mater. Interfaces, 2018, 10, 39307-39318.

33. W. Zhao, J. Kong, Hu, Q. Zhuang, J. Gu and Z. Guo, Nanoscale, 2016, 8, 19983-19994.

34. W. Zhao, Y. Tang, J. Xi and J. Kong, Appl. Surf. Sci., 2015, 326, 276-284.

35. Z. J. Ruan, C. Y. K. Chan, J. W. Y. Lam, Q. Wu, Q. Q. Li, J. G. Qin, B. Z. Tang and Z. Li, J. Mater. Chem. C, 2014, 633-640.

36. C. Luo, T. Jiao, Y. Tang and J. Kong, Adv. Eng. Mater., 2018, 20, 1701168

37. M. I. Lipschutz, T. Chantarojsiri, Y.Y. Dong and T. D. Tilley, J. Am. Chem Soc., 2015, 137, 6366-6372.

38. M. Dehonor, K. Varlot-Masenelli, A. Gonzalez-Montiel, C. Gauthier, J. Y. Cavaille and H. Terrones, Chem. Commun., 2005, 5349-5351.

39. C. Luo, Y. Tang, T. Jiao and J. Kong, ACS Appl. Mater. Interfaces, 2018, 10, 28051-28061.

40. F. Liu, J. Kong, C. Luo, F. Ye, X. Luan, N. Tian, Y. Liu, H. Zhang, J. Gu and Y. Tang, Adv. Compos. Hybrid Mater., 2018, 1, 506-517.

41. Y. Wang, J. Wu, Y. Tang, X. Li, C. Yang, M. Qin, F. Huang, X. Li and Z. Zhang, ACS Appl. Mater. Interface, 2012, 4, 4246-4250.

42. C. Wang, L. Jiao, Y. Han, H. Du, W. Peng, Q. Huan, D. Song, Y. Si, Y. Wang and H. Yuan, J. Phys. Chem. C, 2011,115, 8300-8304.

43. J. Guo, B. Jiang X. Zhang, L. Tang and Y. H. Wen, J. Mater. Chem. A, 2015, 3, 2251-2257.

44. F. M. Zhang, B. Y. Geng and Y. J. Guo, Chem.Eur. J., 2009, 15, 6169-6174.

45. X. W. Lou, D. Deng, J. Y. Lee and L. A. Archer, J. Mater. Chem., 2008, 18, 4397-4401.

46. C. Wang, D. L. Wang, Q. M. Wang and L. Wang, Electrochim. Acta, 2010 55, 6420-6425

47. X. Wang, X. L. Wu, Y. G. Guo, Y. T. Zhong, X. Q. Cao, Y. Ma and J. N. Yao, Adv. Funct. Mater., 2010, 20, 1680-1686.

48. W. Y. Li, L. N. Xu and J. Chen, Adv. Funct. Mater., 2005, 15, 851-857.

49. M. Idrees, S. Batool, J. Kong, Q. Zhuang, H. Liu, Q. Shao, N. Lu, Y. Feng, 
E. K. Wujcik, Q. Gao, T. Ding, R. Wei and Z. Guo, Electrochim. Acta, 2019 , 296, 925-937

50. H. Fei, X. Liu and Z. Li, Chem. Eng. J., 2005, 281, 453-458.

51. S. Liu, J. Wang, J. Wang, F. Zhang, F. Liang and L. Wang, Cryst. Engcomm., 2014, 16, 814-819.

52. Q. Wang, R. Zou, W. Xia, J. Ma, B. Qiu, A. Mahmood, R. Zhao, Y. Yang, D. Xia and Q. Xu, Small, 2015, 11, 2511-2517.

53. W. Kaveevivitchai and A. J. Jacobson, J. Power Sources, 2015, 278, 265273.
54. P. Poizot, S. Laruelle, S. Grugeon, L. Dupont and J. M. Tarascon, Nature, 2000, 407, 496-499.

55. Y. Liu and X. G. Zhang, Electrochim. Acta, 2009, 54, 4180-4185.

56. L. Yan, H. Wang, D. Huang and H. Luo, Eng. Sci., 2018, 1, 4-20

57. G. M. Zhou. D. W. Wang. F. Li, L. L. Zhang, N. Li, Z. S. Wu, L. Wen, G. Q. $\mathrm{Lu}$ and H. M. Cheng, Chem. Mater., 2010, 22, 5306-5313.

58. M. Zhu, J. Yang, Z. Yu, H. Chen and F. Pan, J. Mater.Chem. A, 2017, 5, 7026-7034.

Publisher's Note Engineered Science Publisher remains neutral with regard to jurisdictional claims in published maps and institutional affiliations. 